\title{
A 'test and treat' strategy for elevated wound protease activity for healing in venous leg ulcers.
}

DOI:

10.1002/14651858.CD011753.pub2

\section{Document Version}

Final published version

Link to publication record in Manchester Research Explorer

\section{Citation for published version (APA):}

Norman, G., Westby, M., Stubbs, N., Dumville, J., \& Cullum, N. (2016). A 'test and treat' strategy for elevated wound protease activity for healing in venous leg ulcers. Cochrane Database Syst Rev, (1), [CD011753]. https://doi.org/10.1002/14651858.CD011753.pub2

\section{Published in:}

Cochrane Database Syst Rev

\section{Citing this paper}

Please note that where the full-text provided on Manchester Research Explorer is the Author Accepted Manuscript or Proof version this may differ from the final Published version. If citing, it is advised that you check and use the publisher's definitive version.

\section{General rights}

Copyright and moral rights for the publications made accessible in the Research Explorer are retained by the authors and/or other copyright owners and it is a condition of accessing publications that users recognise and abide by the legal requirements associated with these rights.

\section{Takedown policy}

If you believe that this document breaches copyright please refer to the University of Manchester's Takedown Procedures [http://man.ac.uk/04Y6Bo] or contact uml.scholarlycommunications@manchester.ac.uk providing relevant details, so we can investigate your claim.

\section{OPEN ACCESS}




\section{(E) Cochrane Library}

Cochrane Database of Systematic Reviews

\section{A 'test and treat' strategy for elevated wound protease activity for healing in venous leg ulcers (Review)}

Norman G, Westby MJ, Stubbs N, Dumville JC, Cullum N

Norman G, Westby MJ, Stubbs N, Dumville JC, Cullum N.

A 'test and treat' strategy for elevated wound protease activity for healing in venous leg ulcers.

Cochrane Database of Systematic Reviews 2016, Issue 1. Art. No.: CD011753.

DOI: 10.1002/14651858.CD011753.pub2.

www.cochranelibrary.com 
TABLE OF CONTENTS

HEADER . . . . . . . . . . . . . . . . . . . . . . . . . . . . . . . . . . . . 1

ABSTRACT . . . . . . . . . . . . . . . . . . . . . . . . . . . . . . . . . . . . . . . . . . . .

PLAIN LANGUAGE SUMMARY . . . . . . . . . . . . . . . . . . . . . . . . . . . . . . . . . . . 2

BACKGROUND . . . . . . . . . . . . . . . . . . . . . . . . . . . . . . . . . . . . . . . . .

OBJECTIVES . . . . . . . . . . . . . . . . . . . . . . . . . . . . . . . . . . . . .

METHODS . . . . . . . . . . . . . . . . . . . . . . . . . . . . . . . . . . . . . .

Figure 1. . . . . . . . . . . . . . . . . . . . . . . . . . . . . . . . . . . . . . . .

RESULTS . . . . . . . . . . . . . . . . . . . . . . . . . . . . . . . . . . . . . . . 11

DISCUSSION . . . . . . . . . . . . . . . . . . . . . . . . . . . . . . . . . . . . . . . 12

AUTHORS' CONCLUSIONS . . . . . . . . . . . . . . . . . . . . . . . . . . . . . . . . . . . . .

ACKNOWLEDGEMENTS . . . . . . . . . . . . . . . . . . . . . . . . . . . . . . . . . . . . . .

REFERENCES . . . . . . . . . . . . . . . . . . . . . . . . . . . . . . . . . . . . . . 14

CHARACTERISTICS OF STUDIES . . . . . . . . . . . . . . . . . . . . . . . . . . . . . . . . . . . . .

DATA AND ANALYSES . . . . . . . . . . . . . . . . . . . . . . . . . . . . . . . . . . . . . . . . . . .

APPENDICES . . . . . . . . . . . . . . . . . . . . . . . . . . . . . . . . . . . . . . 24

CONTRIBUTIONS OF AUTHORS . . . . . . . . . . . . . . . . . . . . . . . . . . . . . . . . . . . . . . . 28

DECLARATIONS OF INTEREST . . . . . . . . . . . . . . . . . . . . . . . . . . . . . . . . 28

SOURCES OF SUPPORT . . . . . . . . . . . . . . . . . . . . . . . . . . . . . . . . . . . . . . . . . . . . . . .

DIFFERENCES BETWEEN PROTOCOL AND REVIEW . . . . . . . . . . . . . . . . . . . . . . . . . . . . $\quad 29$

A 'test and treat' strategy for elevated wound protease activity for healing in venous leg ulcers (Review)

Copyright $\odot 2016$ The Cochrane Collaboration. Published by John Wiley \& Sons, Ltd. 


\title{
[Intervention Review]
}

\section{A 'test and treat' strategy for elevated wound protease activity for healing in venous leg ulcers}

\author{
Gill Norman ${ }^{1}$, Maggie J Westby ${ }^{1}$, Nikki Stubbs ${ }^{2}$, Jo C Dumville ${ }^{1}$, Nicky Cullum ${ }^{1}$ \\ ${ }^{1}$ School of Nursing, Midwifery and Social Work, University of Manchester, Manchester, UK. ${ }^{2}$ Wound Prevention and Management \\ Service, Leeds Community Healthcare NHS Trust, St Mary’s Hospital, Leeds, UK \\ Contact address: Gill Norman, School of Nursing, Midwifery and Social Work, University of Manchester, Jean McFarlane Building, \\ Oxford Road, Manchester, M13 9PL, UK. gill.norman@manchester.ac.uk.
}

Editorial group: Cochrane Wounds Group.

Publication status and date: New, published in Issue 1, 2016.

Review content assessed as up-to-date: 4 January 2016.

Citation: Norman G, Westby MJ, Stubbs N, Dumville JC, Cullum N. A 'test and treat' strategy for elevated wound protease activity for healing in venous leg ulcers. Cochrane Database of Systematic Reviews 2016, Issue 1. Art. No.: CD011753. DOI: 10.1002/14651858.CD011753.pub2.

Copyright (C) 2016 The Cochrane Collaboration. Published by John Wiley \& Sons, Ltd.

\section{A B S T R A C T}

\section{Background}

Venous leg ulcers are a common and recurring type of complex wound. They can be painful, malodorous, prone to infection and slow to heal. Standard treatment includes compression therapy and a dressing. The use of protease-modulating treatments for venous leg ulcers is increasing. These treatments are based on some evidence that a proportion of slow to heal ulcers have elevated protease activity in the wound. Point-of-care tests which aim to detect elevated protease activity are now available. A 'test and treat' strategy involves testing for elevated proteases and then using protease-modulating treatments in ulcers which show elevated protease levels.

\section{Objectives}

To determine the effects on venous leg ulcer healing of a 'test and treat' strategy involving detection of high levels of wound protease activity and treatment with protease-modulating therapies, compared with alternative treatment strategies such as using the same treatment for all participants or using a different method of treatment selection.

\section{Search methods}

We searched the following electronic databases to identify reports of relevant randomised clinical trials: The Cochrane Wounds Group Specialised Register (January 2016), the Cochrane Central Register of Controlled Trials (CENTRAL, The Cochrane Library) Issue 12, 2015); Ovid MEDLINE (1946 to January 2016); Ovid MEDLINE (In-Process \& Other Non-Indexed Citations January 2016); Ovid EMBASE (1974 to January 2016); EBSCO CINAHL (1937 to January 2016). We also searched three clinical trials registers, reference lists and the websites of regulatory agencies. There were no restrictions with respect to language, date of publication or study setting.

\section{Selection criteria}

Published or unpublished RCTs which assessed a test and treat strategy for elevated protease activity in venous leg ulcers in adults compared with an alternative treatment strategy. The test and treat strategy needed to be the only systematic difference between the groups.

\section{Data collection and analysis}

Two review authors independently performed study selection; we planned that two authors would also assess risk of bias and extract data.

A 'test and treat' strategy for elevated wound protease activity for healing in venous leg ulcers (Review)

Copyright $\odot 2016$ The Cochrane Collaboration. Published by John Wiley \& Sons, Ltd. 


\section{Main results}

We did not identify any studies which met the inclusion criteria for this review. We identified one ongoing study; it was unclear whether this would be eligible for inclusion.

\section{Authors' conclusions}

Currently there is no randomised evidence on the impact of a test and treat policy for protease levels on outcomes in people with venous leg ulcers.

\section{PLAIN LANGUAGE SUMMARY}

\section{A 'test and treat' strategy for elevated wound protease activity for healing in venous leg ulcers}

\section{What are venous leg ulcers?}

Venous leg ulcers are a common and recurring type of chronic wound. Compression therapy (bandages or stockings) is used to treat venous leg ulcers. Dressings which aim to protect the wound and provide an environment that will help it to heal are used underneath compression. Protease-modulating dressings are one of several types of dressing available.

\section{Why use a test and treat strategy for venous leg ulcers?}

Wounds that are slower to heal are thought to have higher levels of proteases (enzymes that break down proteins). Protease-modulating dressings are designed to lower protease activity and help wounds to heal. A test to detect high levels of protease activity has also been introduced. A 'test and treat' strategy involves testing for elevated proteases and then using protease-modulating treatments in ulcers which show elevated protease levels. It is important to know if using both the test and the treatment together can improve healing of leg ulcers.

\section{What we found}

In January 2016 we searched for as many relevant studies as possible that were randomised controlled trials, and which compared a 'test and treat' strategy with another treatment in people with venous leg ulcers. We did not find any eligible randomised studies. We found one ongoing study which might be relevant but could not obtain any more information on this. Research is still needed to find out if it is helpful to test venous leg ulcers for high levels of protease activity and then treat high levels using protease-modulating treatments. This review is part of a set of reviews investigating different aspects of using protease-modulating treatments in people with venous leg ulcers.

\section{B A C K G R O U N D}

\section{Description of the condition}

Venous leg ulcers are a common and recurring type of complex wound (a wound which heals by secondary intention, i.e. by the growth of new tissue rather than by primary closure). Problems with the leg veins (such as damage to the valves, or blockages) reduce the efficient return of blood to the heart and increase the pressure in the leg veins (Ghauri 2010), which may result in venous leg ulcers. The precise chain of events that links the high venous pressures (chronic venous hypertension) with skin breakdown and a chronic wound is not fully understood (Coleridge Smith 1988; Valencia 2001).

Venous leg ulcers commonly occur on the gaiter region of the lower leg (from just below the ankle up to mid calf). A venous leg ulcer is defined as any break in the skin that has either been present for longer than six weeks or occurs in a person with a history of venous leg ulceration. Differential diagnosis of the type of leg ulcer (i.e. the underlying cause) is made by taking a clinical history, physical examination, laboratory tests and haemodynamic assessment (RCN 2006; SIGN 2010). The latter typically includes an assessment of arterial supply to the leg using the ankle brachial pressure index (ABPI), measured using a hand-held Doppler ultrasound 
scanner. Clinically significant arterial disease as a cause of ulceration is usually ruled out by an ABPI of at least 0.8 (Ashby 2014; NICE 2015; SIGN 2010). True venous ulcers are moist, shallow and irregularly shaped and lie wholly or partly within the gaiter area of the leg. Leg ulcers can be associated with venous disease in combination with vascular disease, which impairs arterial blood supply; in these instances they are said to have a 'mixed aetiology'. Open skin ulceration due solely to limb ischaemia from vascular disease is less common.

Accurate, current estimates of leg ulcer prevalence are hard to identify because most surveys do not differentiate between causes of leg ulceration, or do so per limb but not per patient (Moffatt 2004; Srinivasaiah 2007; Vowden 2009a). Estimates of the prevalence of open leg ulceration (any cause) range from 0.4 to 4.8 cases per 1000 (Graham 2003; Johnson 1995; Walker 2002), with the point prevalence of venous leg ulceration in Australian and European studies being between $0.1 \%$ and $0.3 \%$ (Nelzen 2008). A recent estimate suggests that venous ulceration has a point prevalence of 0.29 cases per 1000 in the United Kingdom (UK), whilst mixed arterial/venous leg ulceration has a point prevalence of 0.11 per 1000 (Hall 2014).

Venous disease is a chronic condition which is characterised by periods of ulceration (i.e., an open wound) followed by healing and then recurrence. An early cross-sectional survey reported that half of current or recent ulcers had been open for up to nine months and that $35 \%$ of people with leg ulcers had experienced four or more episodes (Callam 1987). This picture was supported by a subsequent cross-sectional study (Nelzen 1994).

More recent analysis of almost 1200 patients documented a 24week healing rate of $76 \%$ and a recurrence at one year of $17 \%$ (Gohel 2005). Cohort data from 20,000 people have shown that initial wound area and duration accurately predict healing in venous leg ulcers (Margolis 2004). In this study, ulcers smaller than $10 \mathrm{~cm}^{2}$ with durations of less than 12 months at first visit had a $29 \%$ chance of not healing by the 24 th week of care, whilst ulcers larger than $10 \mathrm{~cm}^{2}$ with duration longer than 12 months had a $78 \%$ chance of not healing by 24 weeks (Margolis 2004). A small cohort study has suggested that percentage change in area over the first four weeks of treatment may be an indicator of whether a wound will heal within 24 weeks (Kantor 2000). Older age has been identified as an independent risk factor for delayed healing (Gohel 2005) while slow healing is also a risk factor for recurrence, possibly because it reflects the extent of underlying venous insufficiency (Gohel 2005).

Venous ulcers are painful, can be malodorous and prone to infection, and may severely affect patients' mobility and quality of life. The presence of leg ulceration has been associated with pain, restriction of work and leisure activities, impaired mobility, sleep disturbance, reduced psychological well-being and social isolation (Herber 2007; Persoon 2004). In severe cases, ulceration can lead to limb amputation, although this may be more common in patients with comorbid arterial insufficiency (Dumville 2009;
Nelzen 1997; Valencia 2001). Recent research suggests that people with complex wounds, including those with venous leg ulcers, commonly see complete wound healing as the most important outcome to them (Madden 2014).

The financial cost of treating an unhealed leg ulcer in the UK has most recently been estimated at around GBP 1700 per year (price year 2012) (Ashby 2014). An earlier evaluation estimated the average cost of treating a venous leg ulcer in the UK (based on costs for material for dressing changes) as between EUR 814 and EUR 1994 and, in Sweden as lying between EUR 1332 and EUR 2585 (price year 2002), with higher costs associated with larger and more chronic wounds (Ragnarson Tennvall 2005). In Bradford, UK, GBP 1.69 million was spent on dressings and compression bandages, and GBP 3.08 million on nursing time (estimates derived from resource use data for all wound types) during the financial year 2006 to 2007 (Vowden 2009b). Data from a German study, which estimated total costs including those classified as indirect or intangible costs, estimated mean annual costs of leg ulcers as EUR 9060 per patient (price year 2006). This figure is higher than other estimates because it includes non-health service costs to the patient and to society (Augustin 2012). These data are all derived from high-income countries and thus may not be a true reflection of costs elsewhere, which may be higher or lower. The first line treatment for venous leg ulcers is compression therapy in the form of bandages, stockings or mechanical devices (O'Meara 2012). This application of external pressure around the lower leg assists venous return and reduces venous reflux (Woo 2013). Alongside compression, wound dressings are commonly applied to open ulcers. The primary rationale for using a dressing is to protect the surface of the ulcer; however other considerations such as absorption of exudate or antimicrobial properties also play a role in treatment selection (O'Meara 2014). Other treatments for venous leg ulcers include venous surgery (removal of incompetent superficial veins) (Gohel 2007) and drugs such as pentoxifylline (Jull 2012). Other standard therapeutic approaches for complex wounds, such as optimising nutrition, and debridement (removal of dead, damaged or infected tissue), may also be offered. Despite these approaches, as discussed above, many venous leg ulcers remain hard to heal and further specialist treatments may be considered.

\section{Description of the intervention}

A 'test and treat' strategy involves the use of a diagnostic/prognostic test or assessment in conjunction with a therapeutic intervention (a treatment): the use and/or timing of the treatment being dependent on the results of the preceding test. A diagnostic test determines the current state of disease while a prognostic test indicates the likely future course of the disease process (Rector 2012). Evaluations of test and treat strategies assess the use of combinations of testing and treating, as opposed to evaluating diagnostic test accuracy/prognostic test value, or the effects of an treat- 
ment, separately. Test and treat approaches are therefore the best method for implementing a test where we need to consider both its diagnostic properties (e.g. sensitivity and specificity) and the healthcare outcomes from an effective test for the relevant indication (Ferrante di Ruffano 2012; Fryback 1991; Guyatt 1986; Lord 2006). As such, test and treat evaluations are pragmatic and give an indication of the real life results of implementing the strategy in terms of its impact on patient outcomes (Bossuyt 2009).

Just as with therapeutic interventions alone, the gold standard for assessing the impact of a test plus a treatment strategy is the randomised controlled trial (RCT) (Lord 2009). Guidance on assessing the impact of tests in health care has been issued by various agencies including the UK National Institute for Health and Care Excellence (NICE 2012) and the United States (US) Agency for Healthcare Research and Quality (AHRQ 2012; Rector 2012).

In this review we evaluate test and treat interventions for high protease activity in venous leg ulcers. This involves the use of a test for high protease levels in venous leg ulcers as well as subsequent targeted treatment decisions (e.g.use of treatments designed to reduce protease levels) which follow the test.

\section{Protease activity in wounds}

Proteases are enzymes which break down proteins into their constituent peptides and amino acids. The action of different proteases tends to be restricted to different proteins. The principal proteases involved in wound healing are the matrix metalloproteinases (MMPs) and the serine proteases which breakdown extracellular matrix (ECM) and connective tissue proteins such as collagen and elastin (Ladwig 2002; Nwomeh 1999).

Proteases are thought to play key roles in the normal wound healing process, being active in three of the phases of wound healing: inflammation, proliferation and remodelling (Trengove 1999). In the inflammation phase, proteases are used for the removal of damaged ECM, bacteria and foreign material (aiding autolytic debridement); in the proliferation phase proteases have a role in the degradation of capillary basement membrane for angiogenesis (growth of new capillary blood vessels) and in aiding detachment and migration of cells; and in the remodelling phase protease activity contributes to contraction and remodelling of scar ECM. It is thought that there is a burst of protease activity at the start of acute wound healing and, in normally-healing wounds, an activity peak in the first two to three days followed by a decline to very low levels after one week (Nwomeh 1998). Proteases may be present in an active or inactive state and protease activity is regulated through complex feedback mechanisms within the wound environment; only activated proteases have an impact on the wound healing process (McCarty 2013; Nwomeh 1999; Yager 2002).

In non-healing wounds it is thought that a complex inflammatory mechanism may result in proteases reaching higher levels and also persisting for longer than in healing wounds (Trengove 1999). Correlations between elevated levels of MMPs and delayed healing have been documented in pressure ulcers (Ladwig 2002) and foot ulcers in people with diabetes ( Liu 2009) as well as in venous leg ulcers (Mwaura 2006; Serra 2013). However, there is limited evidence for a causal relationship between protease activity and wound healing.

\section{Protease-modulating treatments}

Novel treatments have been designed to modify the chronic wound environment by substantially reducing the activity of key proteases. The principle of such protease-modulating matrix treatments is both to absorb and bind excess proteases from wound fluids, thereby reducing levels of protease at the wound bed (Cullen 2002). The treatments do not, however, affect the expression of proteases on a cellular level (Lobmann 2006).

Interventions that reduce harmful levels of protease activity may potentially promote healing in wounds with persistently high protease activity. However evidence for this from RCTs has been limited across unselected wounds of different aetiologies, including venous leg ulcers (e.g. Andriessen 2009; Chin 2003; Kakagia 2007; Nisi 2005; Veves 2002). There is extremely limited evidence from a very small industry-sponsored study that screened wounds may respond better to protease-modulating treatment relative to all wounds (Cullen 2011).

Treatments can target specific proteases or can be broader spectrum, designed to inhibit all protease activity. Common proteasemodulating treatments and their properties are described below. Products are listed by their generic names and, when possible, with examples of corresponding trade names and manufacturers. Both dressings and ointments are available; some dressings have silver ions incorporated, which are intended to reduce wound pathogens. Types of protease-modulating treatment which are listed in the British National Formulary (BNF 2015) include the following:

- Starch-based ointment: Cadesorb® (Smith \& Nephew)

- Collagen matrix (bovine cartilage): Catrix ${ }^{\circledR}$ (Cranage)

- Collagen matrix (bovine cartilage): Suprasorb® C (Activa)

- Collagen and oxidised regenerated cellulose matrix dressing: Promogran ${ }^{\circledR}$ (Systagenix) Collagen, silver and oxidised regenerated cellulose matrix dressing: Promogran ${ }^{\circledR}$ Prisma ${ }^{\circledR}$ (Systagenix)

- Cellulose acetate matrix, impregnated with polyhydrated ionogens ointment in polyethylene glycol basis dressing: Tegaderm ${ }^{\circledR}$ Matrix $(3 \mathrm{M})$

- Adherent polymer matrix dressing containing nanooligosaccharide factor (NOSF), with polyurethane foam film backing: UrgoStart ${ }^{\circledR}$ (Urgo)

- Non-adherent wound contact dressing containing NOSF: UrgoStart ${ }^{\circledR}$ Contact (Urgo).

This list is not exhaustive and other wound dressings such as Aquacel ${ }^{\circledR}\left(\right.$ ConvaTec) and Xelma ${ }^{\circledR}$ (Mölnycke) are sometimes listed as having protease-modulating effects (Wound Care Handbook). A pragmatic approach will be adopted, and where such dressings 
are used in a protease-modulating capacity we will include them in the review.

\section{How the intervention might work}

Very weak evidence from an unadjusted analysis suggests an inverse association between protease levels and wound healing in a mixed sample that included people with venous leg ulcers, foot ulcers in people with diabetes, and pressure ulcers (Cullen 2011; Serena 2011). On this basis, a test and treat process has been proposed, which involves the point-of-care testing of venous leg ulcers for levels of protease activity followed by targeted treatment of those deemed to have high levels of protease activity (and alternative care for the remaining wounds) (Systagenix 2013). This might mean that only wounds where high protease activity is present receive treatment designed to lower it. It is suggested that this strategy may reduce the time taken to heal for the wounds receiving targeted treatment, whilst avoiding unnecessary, expensive and possibly harmful use of the protease-modulating treatments in wounds where protease activity levels were not increased, and allowing more appropriate alternative treatments.

\section{Why it is important to do this review}

Venous leg ulcers are a relatively common type of complex wound that have a negative impact on people's lives and incur high costs for health services and society. Leg ulcers are painful, sometimes malodorous, prone to infection, and may severely affect patients' mobility and quality of life, and in severe cases, there is a risk of limb amputation. There are a number of treatments for venous leg ulcers, but many ulcers prove hard to heal.

There is a widespread view among clinical experts in the field that proteases have an important role in wound healing and that a point-of-care test for elevated activity of commonly identified proteases has value (Barrett 2011; International Consensus 2011; Snyder 2011; Snyder 2012). Identification of wounds in which there is elevated protease activity is not considered possible on the basis of clinical examination alone; delayed wound healing is not proposed to be a universal indicator (Sibbald 2012; Snyder 2012). Limited data from an industry-sponsored study found that only $28 \%$ of 162 non-healing wounds of mixed aetiology were determined to have high protease activity (Serena 2011).

However, although a test for protease activity is now available, the impact of its use, in combination with subsequent targeted treatments with protease-modulating therapies where indicated, is unclear, and we are not aware of other reviews that address this question. A Cochrane review of the use of protease-modulating dressings in venous leg ulcers is currently underway (Westby 2015). A review of the prognostic value of protease activity tests is also planned.
In the current review we assess the impact of testing venous leg ulcers for high levels of protease activity and selectively treating with protease-modulating interventions those wounds which record a positive test result; we therefore assess the effectiveness of one or more tests for protease activity (together with thresholds for treatment) and the subsequent protease-modulating treatments compared to an alternative treatment strategy. Alternative treatment approaches would include using a different test and treat strategy, using protease-modulating treatments in all participants or using a different type of treatment or a standard care approach where other factors are used to guide treatment decisions.

\section{O B JE C T IVES}

To determine the effects on venous leg ulcer healing of a 'test and treat' strategy involving detection of high levels of wound protease activity and selective treatment with protease-modulating therapies compared with alternative treatment strategies, such as using the same treatment for all participants or using a different method of treatment selection.

\section{METHODS}

\section{Criteria for considering studies for this review}

\section{Types of studies}

Published and unpublished randomised controlled trials (RCTs), including cluster RCTs, irrespective of the language of report. We excluded quasi-randomised studies. We included RCTs reported only as abstracts when available data (either from the abstract itself or from the study authors) were sufficient for reasonable data extraction.

\section{Types of participants}

Trials recruiting adults described as having venous leg ulcers, managed in any setting were eligible for inclusion. We accepted study authors' definitions of venous leg ulcers.

Trials involving people with other types of complex wounds were eligible if the results for people with venous leg ulcers were presented separately or were available from the authors.

Trials involving participants at any stage in their treatment pathway, e.g. participants with or without hard to heal ulcers and with or without clinical infection of ulcers, were eligible. 


\section{Types of interventions}

RCTs which evaluated a 'test and treat strategy' for elevated protease activity in venous leg ulcers were eligible for inclusion. In these studies the use of a specific 'test and treat' strategy needed to be the only systematic difference between treatment groups. Eligible trials included those in which all participants in the comparison arm received the same protease-modulating treatment but where a 'test and treat' strategy was applied in the intervention arm, as well as trials comparing test and treatment combinations versus each other, versus other interventions, or versus standard care. Comparisons of different test thresholds for the same test were also eligible.

RCTs were eligible for inclusion whether or not compression therapy was reported as a concurrent treatment, as long as the study groups received the same compression protocols.

We excluded studies in which the test result was an inclusion criterion, i.e. participants with a positive test result were randomised to different protease-modulating treatments or to protease-modulating versus alternative treatments, as these will be included in a concurrent review evaluating protease-modulating matrix treatments for venous leg ulcers (Westby 2015).

\section{Types of outcome measures}

\section{Primary outcomes}

The primary effectiveness outcome for this review was wound healing. Trialists use a range of different methods of measuring and reporting this outcome. We regard the following as the most relevant and rigorous measures of wound healing:

- Time to complete wound healing (correctly analysed using survival, time-to-event approaches). Ideally the outcome would be adjusted for appropriate covariates, e.g. baseline ulcer area/ duration.

- Proportion of wounds completely healed during follow-up (frequency of complete healing).

We planned to use and report authors' definitions of complete wound healing.

We planned that, where both of the outcomes above were reported, we would present all data in a summary outcome table for reference but would focus on reporting time to healing. When time was analysed as a continuous measure, but it was not clear whether all wounds had healed, we planned to document the use of the outcome in the study but not to extract, summarise or use the data in any meta-analysis.

The primary safety outcome was all reported adverse events. We planned to extract data on all serious adverse events and all nonserious adverse events where a clear methodology for the collection of adverse event data was provided. This methodology needed to make it clear whether events were reported at the participant level or, where multiple events/person were reported, that an appropriate adjustment had been made for data clustering. We did not plan to extract individual types of adverse events other than pain or infection (see Secondary outcomes). We intended to note where events were reported as being treatment-related.

\section{Secondary outcomes}

- Health-related quality of life: we planned to include quality of life where it was reported using a validated scale such as the SF36 or EQ-5D, or a validated disease-specific questionnaire such as the Cardiff Wound Impact Schedule. Ideally, reported data would have been adjusted for the baseline score. We did not plan to include ad hoc measures of quality of life that are unlikely to be validated and would not have been common to multiple trials.

- Pain scores: we planned to include pain (including pain at dressing change) only where mean scores with a standard deviation were reported using a scale validated for the assessment of pain levels, such as a visual analogue scale (VAS).

- Change (and rate of change) in wound size, with adjustment for baseline size (we planned to contact study authors to request adjusted means when not presented): when change or rate of change in wound size was reported without adjustment for baseline size, we planned to document the use of the outcome in the study, but not to extract, summarise or use the data in any meta-analysis.

- Change in wound infection status (as defined by the study authors): we planned to include measures of incident cases of infection and cases of existing infections being resolved. We did not plan to extract data on microbiological assays not clearly linked to a diagnosis of infection. We intended to use authors' definitions of infection.

- Resource use (when presented as a mean with standard deviation) including measures of resource use such as appointments for undergoing tests and receiving test results, number of dressing changes, number of nurse visits, length of hospital stay, need for other interventions.

- Costs associated with resource use (including estimates of cost-effectiveness).

If a trial was otherwise eligible (correct study design, population and intervention/comparator) but did not report a listed outcome, then we planned to contact the study authors where possible in order to establish whether a relevant outcome was measured but not reported. We planned to include trials only where we were able to obtain data on a listed outcome.

We planned to report outcome measures at the latest time point available for a study (assumed to be length of follow-up if not specified) and the time point specified in the methods as being of primary interest (if this is different from the latest time point available). We planned that, where appropriate, all outcomes would be classed (and categorised) from:

- < 1 week to 8 weeks as short term; 
- 8 weeks to 24 weeks as medium term; and

- 24 weeks as long term.

We planned to use our judgement to decide whether statistical pooling within these time categories was appropriate.

\section{Search methods for identification of studies}

\section{Electronic searches}

We searched the following electronic databases:

- The Cochrane Wounds Group Specialised Register

(January 2016).

- The Cochrane Central Register of Controlled Trials

(CENTRAL, The Cochrane Library) (Issue 12, 2015).

- Ovid MEDLINE (1946 to January 2016).

- Ovid MEDLINE (In-Process \& Other Non-Indexed Citations) (January 2016).

- Ovid EMBASE (1974 to January 2016).

- EBSCO Cumulative Index to Nursing and Allied Health Literature (CINAHL) (1937 to January 2016).

We used the following search strategy in CENTRAL:

\#1 MeSH descriptor: [Leg Ulcer] explode all trees

\#2 (varicose ulcer* or venous ulcer* or leg ulcer* or stasis ulcer* or crural ulcer* or ulcus cruris or ulcer cruris):ti,ab,kw (Word variations have been searched)

\#3 \{or \#1-\#2\}

\#4 MeSH descriptor: [Peptide Hydrolases] explode all trees \#5 (protease* or proteinase* or metalloproteinase* or peptidase* or "peptide hydrolase" or "peptide hydrolases" or "proteolytic enzymes" or "proteolytic enzyme" or esteroprotease*):ti,ab,kw (Word variations have been searched)

\#6 \{or \#4-\#5\}

$\# 7$ and \#3, \#6\} in Trials

The search strategies for Ovid MEDLINE, Ovid EMBASE and EBSCO CINAHL can be found in Appendix 1. We adapted the CENTRAL strategy to search these three databases. We combined the Ovid MEDLINE search with the Cochrane Highly Sensitive Search Strategy for identifying randomised trials in MEDLINE: sensitivity- and precision-maximising version (2008 revision) ( Lefebvre 2011). We combined the EMBASE search with the Ovid EMBASE filter developed by the UK Cochrane Centre (Lefebvre
2011). We combined the CINAHL searches with the trial filters developed by the Scottish Intercollegiate Guidelines Network ( SIGN 2011). There were no restrictions with respect to language, date of publication or study setting.

We also searched the following clinical trials registries:

- ClinicalTrials.gov (clinicaltrials.gov).

- WHO International Clinical Trials Registry Platform ( who.int/trialsearch).

- EU Clinical Trials Register (clinicaltrialsregister.eu).

\section{Searching other resources}

We tried to identify other potentially-eligible trials or ancillary publications by searching the records retrieved by the search strategy for the review of effectiveness of protease-modulating treatment (Westby 2015) together with the reference lists of trials which were included in that review. We also searched the references of relevant systematic reviews, meta-analyses and health technology assessment reports. We contacted Systagenix who are the manufacturers and distributors of the available point-of-care test for wound protease activity. We searched the websites and briefing documentation of regulatory bodies including the US Food and Drug Administration and the European Medical Association. We also planned to contact corresponding authors of included trials.

\section{Data collection and analysis}

\section{Selection of studies}

Two review authors independently assessed the titles and abstracts of the citations retrieved by the searches for relevance. They also independently assessed the titles and abstracts of records retrieved by the search strategy for the review of effectiveness of proteasemodulating treatments (Westby 2015).

After this initial assessment, we obtained full text copies of all studies considered to be potentially relevant. Two review authors independently checked the full papers for eligibility; disagreements were resolved by discussion and, where required, the input of a third review author. Where the eligibility of a study was unclear, we attempted to contact study authors. We recorded all reasons for exclusion of studies for which we had obtained full copies. We completed a PRISMA flowchart to summarise this process (Liberati 2009) (Figure 1). 
Figure I. PRISMA Study flow diagram

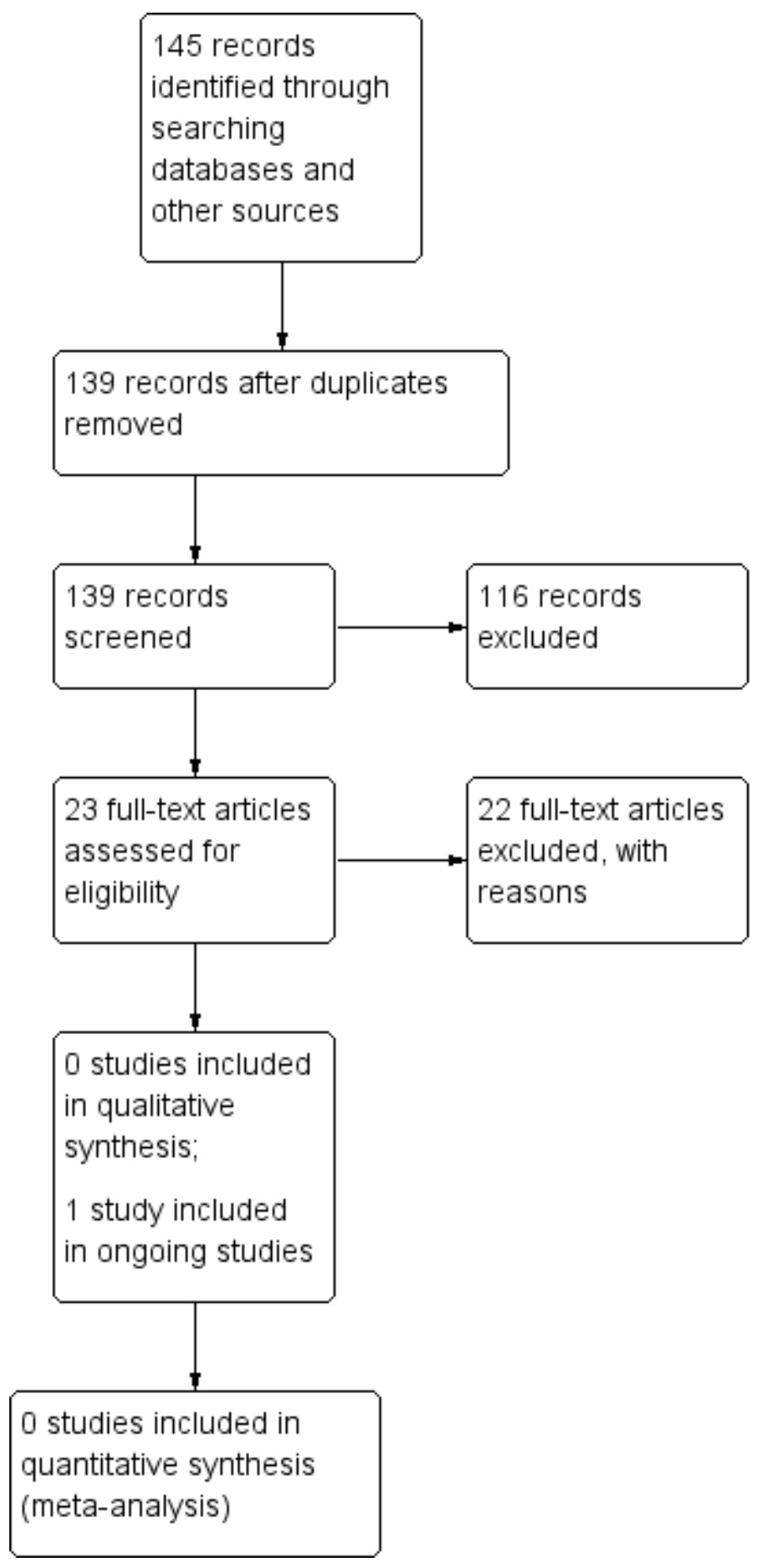


Where studies were reported in multiple publications/reports, we obtained all associated publications. Whilst studies would be included only once in the review, we planned to extract data from all reports to ensure that all available relevant data were obtained.

\section{Data extraction and management}

We planned to extract and summarise details of the eligible studies. Where possible we planned to extract data by treatment group for the prespecified interventions and outcomes in this review. We intended that two review authors would independently extract data; discrepancies were to be resolved through discussion or by consultation with a third author. Where data were missing from reports, we planned to contact the study authors to request this information.

Where a study with more than two intervention arms was included, we planned to extract only data from intervention and control groups that met the eligibility criteria. Where the reported baseline data related to all patients rather than to those in relevant treatment arms, we planned to extract the data for the whole trial and note this.

We planned to collect outcome data for relevant time points as described in the Types of outcome measures section, and to do this on an intention-to-'test and treat' basis. However, where possible, we planned also to extract separate outcome data for those in the intervention arm who had positive test results followed by protease-modulating treatment and those who had negative test results followed by a different treatment.

Where possible we planned to extract the following data:

- bibliographic data including date of completion/publication

- country of origin

- unit of randomisation (participant/ulcer)

- unit of analysis

- trial design, e.g. parallel; cluster

- care setting

- number of participants randomised to each trial arm and number included in final analysis

- eligibility criteria and key baseline participant data including duration of venous insufficiency and current ulcer(s)

- details of treatment regimen received by each group including the nature, threshold and timing of test and the nature, timing and duration of subsequent treatment initiation. Details of treatment for participants with negative test results would also have been reported

- details of any co-interventions

- number (\%) of patients with positive and negative test results and the number of patients receiving each treatment

- primary and secondary outcome(s) (with definitions and, where applicable, time points)

- outcome data for primary and secondary outcomes (by group) including outcomes for participants randomised to the intervention(s) but with negative test results

- duration of follow-up

- number of withdrawals (by group), and number of withdrawals (by group) due to adverse events. Where possible, separate data would have been extracted for participants in the intervention group(s) with positive and negative test results

- publication status of trial

- source of funding for trial.

\section{Assessment of risk of bias in included studies}

We planned that two review authors would independently assess included studies using the Cochrane Collaboration tool for assessing risk of bias (Higgins 2011a). This tool addresses six specific domains: sequence generation, allocation concealment, blinding, incomplete outcome data, selective outcome reporting and other issues (Appendix 2). In this review we planned to record issues with unit of analysis, for example where a cluster trial has been undertaken but analysed at the individual level in the study report. For this review we did not plan to assess blinding of patients and personnel as it was considered unlikely to be possible in a trial of the interventions included (testing and treating according to test results); we planned to assess all other domains. We planned to assess blinding of outcome assessment and completeness of outcome data for each of the review outcomes separately. Because this is a review of a test and treat process, we also planned to consider differences in completeness of outcome data between patients with positive versus negative test results in the intervention group(s).

We planned to present our assessment of risk of bias using two 'Risk of bias' summary figures; one a summary of bias for each item across all studies, and a second showing a cross-tabulation of each trial by all of the 'Risk of bias' items. We planned to summarise a study's risk of selection bias, detection bias, attrition bias, reporting bias and other bias. We anticipated that, in many comparisons, blinding of participants and personnel may not have been possible. Therefore the assessment of the risk of detection bias would have focused on whether blinded outcome assessment was reported. (Because wound healing can be a subjective outcome, it can be at high risk of measurement bias when outcome assessment is not blinded). For trials using cluster randomisation, we also planned to examine the risk of bias considering: recruitment bias, baseline imbalance, loss of clusters, incorrect analysis and comparability with individually randomised trials (Higgins 2011b) (Appendix $3)$.

\section{Measures of treatment effect}

We planned to report time-to-event data (e.g. time to complete wound healing) as hazard ratios (HRs) when possible, in accor-

A 'test and treat' strategy for elevated wound protease activity for healing in venous leg ulcers (Review) 
dance with the methods described in theCochrane Handbook for Systematic Reviews of Interventions (Deeks 2011). If studies reporting time-to-event data (e.g. time to healing) did not report an $\mathrm{HR}$, then, when feasible, we planned to estimate this using other reported outcomes, such as numbers of events, through the application of available statistical methods (Parmar 1998; Tierney 2007). For dichotomous outcomes, we intended to calculate the risk ratio (RR) with $95 \%$ confidence intervals (CIs). For continuous outcome data, we planned to use the mean difference (MD) with $95 \%$ CIs for trials that used the same assessment scale. When trials used different assessment scales, we planned to use the standardised mean difference (SMD) with 95\% CIs.

\section{Unit of analysis issues}

Where studies were randomised at the participant level and outcomes measured at the wound level, for example for wound healing, we anticipated treating the participant as the unit of analysis when the number of wounds assessed appeared to be equal to the number of participants (e.g. one wound per person).

A possible unit of analysis issue that was anticipated was randomisation carried out at the participant level with the allocated treatment used on multiple wounds per participant (or perhaps only on some participants) but data presented and analysed per wound (clustered data).

In cases where included studies contained some or all clustered data we planned to report this, noting whether data had been (incorrectly) treated as independent. We planned to record this as part of the 'Risk of bias' assessment. We did not plan to undertake further calculation to adjust for clustering as part of this review.

\section{Dealing with missing data}

It is common to have data missing from trial reports. Excluding participants from the analysis post randomisation or ignoring participants who are lost to follow-up compromises the randomisation and may introduce bias into the trial. If it was thought that study authors might be able to provide some missing data, we planned to contact them; however data will often be missing because of loss to follow-up. In individual studies, when data on the proportion of ulcers healed were presented, we planned to assume that randomly assigned participants not included in an analysis had an unhealed wound at the end of the follow-up period (i.e. they would be considered in the denominator but not in the numerator).

When a trial did not specify participant group numbers before dropout, we planned to present only complete case data. For time to-healing analysis using survival analysis methods, dropouts should be accounted for as censored data. Hence all participants would contribute to the analysis. We acknowledge that such analysis assumes that dropouts are missing at random and there is no pattern of missingness. We planned to present data for all secondary outcomes as a complete case analysis.
For continuous variables, e.g. length of hospital stay, and for all secondary outcomes, we planned to present available data from the study reports/study authors and not to impute missing data. Where measures of variance were missing we planned to calculate these wherever possible (Higgins 2011a). If calculation was not possible we planned to contact study authors. Where these measures of variation remained unavailable and could not be calculated, we planned to exclude the study from any relevant metaanalyses.

\section{Assessment of heterogeneity}

Assessment of heterogeneity can be a complex, multi-faceted process. Firstly, we planned to consider clinical and methodological heterogeneity: that is the degree to which the included studies varied in terms of participant, intervention, outcome and characteristics such as length of follow-up. We planned to supplement this assessment of clinical and methodological heterogeneity by information regarding statistical heterogeneity - assessed using the $\mathrm{Chi}^{2}$ test (a significance level of $\mathrm{P}<0.10$ would be considered to indicate statistically significant heterogeneity) in conjunction with $\mathrm{I}^{2}$ measure (Higgins 2003). I ${ }^{2}$ examines the percentage of total variation across RCTs that is due to heterogeneity rather than chance (Higgins 2003). Very broadly, we would consider that $I^{2}$ values of $25 \%$, or less, may mean a low level of heterogeneity (Higgins 2003 ), and values of $75 \%$, or more, indicate very high heterogeneity (Deeks 2011). We also planned to examine the variability of the point estimates and the overlap of the confidence intervals, when $\mathrm{I}^{2}$ values were less than $50 \%$. Where there was evidence of high heterogeneity we intended to attempt to explore this further; see Data synthesis.

\section{Assessment of reporting biases}

Reporting biases arise when the dissemination of research findings is influenced by the nature and direction of results. Publication bias is one of a number of possible causes of 'small study effects', that is, a tendency for estimates of the intervention effect to be more beneficial in smaller RCTs. Funnel plots allow a visual assessment of whether small study effects may be present in a metaanalysis. A funnel plot is a simple scatter plot of the intervention effect estimates from individual RCTs against some measure of each trial's size or precision (Sterne 2011). Funnel plots are only informative when there are a substantial number of studies included in an analysis; we planned to present funnel plots for meta-analyses which included at least 10 RCTs using RevMan 5.3 (RevMan 2014).

\section{Data synthesis}

We anticipated reporting details of included studies in narrative review according to the comparison between intervention and comparator, the population and the time point of the outcome 
measurement. We also planned to use the timing of the protease activity test and the threshold for a positive result to structure the synthesis. We planned to consider clinical and methodological heterogeneity and undertake pooling when studies appeared appropriately similar in terms of ulcer characteristics, intervention type, duration of treatment and outcome assessment.

Our standard approach for meta-analysis would have been to employ a random-effects model. Our preference for the more conservative random-effects model is based on the fact that statistical assessments can miss potentially important between-study heterogeneity in small samples (Kontopantelis 2012).

A fixed-effect analysis would only have been used when, in the judgement of the review authors, there was minimal clinical heterogeneity and this was also supported by an $\mathrm{Chi}^{2}$ value estimated to be statistically non-significant and an $\mathrm{I}^{2}$ of $0 \%$ (Kontopantelis 2013). In all other circumstances a random-effects model would have been adopted. Where clinical heterogeneity was thought to be acceptable or of interest we might have meta-analysed even when statistical heterogeneity was high, but we would have attempted to interpret the causes behind this heterogeneity and would have considered using meta-regression for that purpose, if possible (Thompson 1999; Thompson 2002).

We planned to present data using forest plots where possible. For time-to-event data, we planned to plot (and, if appropriate, pool) estimates of HRs and 95\% CIs as presented in the study reports using the generic inverse variance method in RevMan 5.3 (RevMan 2014). Where time to healing was analysed as a continuous measure but it was not clear if all wounds healed, we intended to document the use of the outcome in the study but not summarise or use the data in any meta-analysis. For dichotomous outcomes we intended to present the summary estimate as an RR with $95 \%$ CI. Where continuous outcomes were measured in the same way across studies, we planned to present a pooled MD with $95 \% \mathrm{CI}$; we planned to pool SMD estimates where studies measured the same outcome using different methods.

\section{'Summary of findings' tables}

We planned to present the main results of the review in 'Summary of findings' tables. These tables would have presented key information concerning the quality of the evidence, the magnitude of the effects of the interventions examined and the sum of available data for the main outcomes (Schünemann 2011a). The 'Summary of findings' tables would also have included an overall grading of the evidence related to each of the main outcomes using the GRADE (Grades of Recommendation, Assessment, Development and Evaluation) approach. The GRADE approach defines the quality of a body of evidence as the extent to which one can be confident that an estimate of effect or association is close to the true quantity of specific interest. The quality of a body of evidence involves consideration of within-trial risk of bias (methodological quality), directness of evidence, heterogeneity, precision of effect estimates and risk of publication bias (Schünemann 2011b). We planned to present the following outcomes in the 'Summary of findings' tables for each comparison:

- Time to complete ulcer healing when analysed using appropriate survival analysis methods.

- Proportion of ulcers completely healed during the trial period.

- Study-defined serious and non-serious adverse events.

\section{Subgroup analysis and investigation of heterogeneity}

We planned that, when possible, we would perform subgroup analyses according to whether the intervention was delivered in conjunction with compression therapy or not. RCTs in which it was unclear whether concurrent compression therapy was used would have been excluded from these analyses or categorised separately. When possible we planned to conduct subgroup analyses based on the type of test for protease activity employed and/or the threshold used to define a positive test result. For example laboratory-based assays could have been compared to point-of-care tests. When possible, we planned to explore the influence of risk of bias on effect size.

We planned to assess the influence of removing from meta-analyses studies classed as having high and unclear risk of bias. We planned to explore subgroups of studies assessed as having low risk of bias in all key domains, namely selection bias, detection bias and attrition bias.

Elements of this methods section are based on the standard Cochrane Wounds Group Protocol Template.

\section{R E S U L T S}

\section{Description of studies}

\section{Results of the search}

The search retrieved 139 unique records. We obtained 23 full publications as potentially relevant to this review. Reference checking of relevant reviews did not identify any additional records. There were no studies which met the inclusion criteria for this review (Figure 1). As an additional measure, and to ensure we did not miss any potentially relevant records, we also searched 201 unique records retrieved by the search strategy for a related review (Westby 2015) and assessed 48 of these as full text; none of these records were subsequently included in the review.

\section{Included studies}

There were no included studies and there were no studies which were awaiting assessment. 


\section{Ongoing studies}

We identified a clinical trials record for one ongoing RCT (NCT 01537003 ) which appeared to be potentially relevant. An attempt in June 2015 to contact the sponsoring pharmaceutical company (Systagenix) to establish more information about this study and planned publication was unsuccessful. This study was registered in February 2012 and is listed as last verified May 2013, at which time its status was "recruiting". The estimated study completion date was January 2014 with a primary completion date for primary outcome data collection of October 2013.

This study is described as a multi-centre randomised open-label trial conducted at centres in the United States, the United Kingdom, Germany and Italy. The purpose of the trial is stated to be, "to determine if wounds with elevated protease activity (EPA) treated with targeted interventions such as protease modulating therapies can improve clinical and economic outcomes". Its planned recruitment is 250 patients with venous leg ulcers with a duration of between six weeks and three years, a wound size of between 1 and $100 \mathrm{~cm}^{2}$, and no signs of infection. People with diabetes are excluded from the trial (see Ongoing studies).

The authors state that wounds with EPA will be determined using a new point-of-care diagnostic test, and the efficacy of a proteasemodulating therapy will be determined against standard care in both elevated EPA and low protease activity wounds. They define four groups of participants:

- Low protease activity treated with oxidised regenerated cellulose (ORC)/collagen plus 2-layer compression bandage (A)

- Low protease activity treated with 2-layer compression bandage alone (B)

- High protease activity treated with ORC/collagen plus 2layer compression bandage (C)

- High protease activity treated with 2-layer compression bandage alone (D)

It is not clear from the available information but it appears that wounds may be tested for EPA before participants are randomised, in order to identify the high and low EPA groups receiving each treatment.

The primary outcomes of the study appear to be:

- Identification of wounds with elevated protease levels using the WOUNDCHEK ${ }^{T M}$ diagnostic test

- Wound healing: Improved healing is defined as the proportion of wounds which achieved at least a $30 \%$ reduction in wound surface area over a four week time frame.

Secondary outcomes are listed as:

- Mean ("average") percentage changes from baseline in protease activity levels after 12 weeks treatment

- Proportion of wounds achieving closure (restoration of complete epithelial cover) at 12 weeks

- Mean (average) time to wound closure

- Relative cost-effectiveness of appropriately targeted therapies: ORC/collagen for wounds with elevated protease activity and standard care for wounds with low protease activity.

The trial appears to assess the randomised use of protease-modulating treatments plus compression versus compression alone in patients whose protease activity status is known (and classified as "elevated" or "low"), as a result of using the WOUNDCHEK ${ }^{T M}$ test for elevate protease activity, but it is not clear how the trial was designed. On the basis of the available information it is unclear whether or not this study assesses a test and treat strategy and therefore whether it meets the inclusion criteria for this review.

\section{Excluded studies}

We excluded 22 studies (Characteristics of excluded studies). Of these, nine were excluded because they did not assess a test and treat approach to venous leg ulcers but simply evaluated the use of protease-modulating treatments in venous leg ulcer or mixed populations, or in other types of wounds.

One excluded study randomised 56 participants with venous leg ulcers to collagen/ORC or collagen/ORC silver and then tested the wounds for elastase (a type of protease) activity at baseline and at intervals during the trial (Cullen 2012). This study was published in abstract form only. This was the only completed trial we identified which both tested for protease activity and randomised patients, but it did not evaluate a test and treat strategy.

Other studies were excluded because they evaluated a different intervention (five studies) or were not randomised trials (eight studies).

One study identified from the search results for the review of protease-modulating therapies (Westby 2015) appeared to evaluate a relevant test and treat approach in foot ulcers in patients with diabetes (Anichini 2013). This study was published in abstract form only. It enrolled 20 people with diabetes and foot ulcers with a minimum of 6 weeks duration. Participants were randomised to testing for elevated protease activity (test not specified) followed by treatment based on that test result, versus no testing and standard care (not further described) for all wounds.

\section{Risk of bias in included studies}

It was not possible to undertake a 'Risk of bias' assessment because no studies met the inclusion criteria.

\section{Effects of interventions}

Neither a meta-analysis nor narrative synthesis of studies was possible because no studies met the inclusion criteria. 


\section{Summary of main results}

Despite extensive searching of electronic databases, clinical trials registers and websites of regulatory agencies we did not identify any completed (published)studies which met the inclusion criteria for this review. The studies excluded from the review were primarily studies which assessed the use of protease-modulating treatments for venous leg ulcers, for mixed populations including venous leg ulcers or for other types of wounds, without assessing the use of a test for elevated protease activity. Others were not RCTs. One trial of protease-modulating treatments in venous leg ulcers did test for elevated activity of a type of protease but did not use the test results as a means of determining treatment decisions (Cullen 2012).

We identified one trial record from the registers of ongoing trials. No outcome data from this trial have been published and attempts to contact the sponsoring company's trial coordinator for more information and/or outcome data were unsuccessful, although the trial's planned completion date has been reached. This trial may be relevant to the review question, based on the limited information available (NCT 01537003), but without further information we cannot determine whether this trial would meet the inclusion criteria for our review. In the study it appears that the test for elevated protease activity may be used in all participants, but it is not clear whether the results of the test dictate subsequent treatment.

\section{Potential biases in the review process}

The review considered as much evidence as possible. There were no restrictions on the language of studies assessed. As well as searching for published studies in databases we have searched trial registers and the websites of regulatory authorities, as well as contacting the company which manufactures the current test for elevated protease activity. We identified one unpublished study, about which we have attempted unsuccessfully to obtain more information. It is possible, however, that there may be additional unpublished data that we have not been able to access.

We have considered whether using broader inclusion criteria would have resulted in a non-empty review (Yaffe 2012). Considering the studies which were excluded from the review it is clear that using less rigorous methodological criteria - for example including non-randomised controlled clinical trials (CCTs) - would not have changed this; the studies excluded as non-RCTs were either uncontrolled or did not assess a relevant test and treat strategy (or both). The only change which might have resulted in the review identifying studies eligible for inclusion would have been to include trials recruiting people with different types of wounds. As we did not search for these trials, we cannot know whether the evidence base would have been substantive. There may, however, be a case for conducting reviews of test and treat strategies in other wound types, in line with the move towards treating different types of chronic wounds separately.

\section{Agreements and disagreements with other studies or reviews}

This is the first review of a 'test and treat' strategy for venous leg ulcers, and no reviews exist of the strategy in other types of wounds. The UK's National Institute for Health and Care Excellence (NICE) has produced a Clinical Knowledge Summary of guidance on the treatment of venous leg ulcers (NICE 2015). This is based on the most recent clinical guidelines (RCN 2006; SIGN 2010) and those of the Wound Healing Society (Robson 2006) and on Cochrane reviews of compression therapy and dressings for venous leg ulcers (Nelson 2014; O’Meara 2012; O’Meara 2013a; O'Meara 2013b). The summary states that compression is the gold standard for treatment and that dressings should be used to prevent wound adherence to compression devices. It advises that there is insufficient evidence to show that any dressing is better than simple low adherent dressings; and there is no mention of assessing or testing the wound before using specialist dressings. This guidance is in line with the findings of other, non-Cochrane reviews (Bouza 2005; Greer 2013, O’Donnell 2006). A suite of updated Cochrane reviews of different dressings for venous leg ulcers is being undertaken, one of which will address the effectiveness of protease-modulating matrix treatments (Westby 2015).

\section{AUTHORS' CONCLUSIONS}

\section{Implications for practice}

An extensive search did not identify any studies assessing the impact of a 'test and treat' strategy for the use of protease-modulating treatments in people with venous leg ulcers. Practitioners may, therefore, elect to take other considerations into account in choosing management strategies for this clinical group. These considerations may include costs and the wound/symptom management properties of dressings.

\section{Implications for research}

Currently there is no evidence on the impact of a test and treat strategy for elevated protease levels on outcomes in people with venous leg ulcers. The fact that we did not find any included studies identifies a significant gap in the evidence base in this area. People with venous leg ulcers were part of the mixed population in which the available test for elevated protease activity was evaluated (Cullen 2011; Serena 2011) and are a major part of the clinical population at which it is targeted.

The idea of treating elevated levels of proteases fundamentally assumes that high levels of proteases are related to reduced healing. It is not clear what the underlying evidence is for such a prognostic relationship, and a review of this is warranted. 
Nevertheless, a test and treat approach for elevated protease levels is currently available, and marketed to health professionals in a number of countries. A robust RCT incorporating an economic evaluation is required to determine if such an approach is clinically effective and if expenditure is likely to be worthwhile.

Such a trial would compare the effect of testing participants' ulcers for elevated protease activity and then treating the wound on the basis of the test result, versus an alternative treatment strategy. Any trial which is undertaken would need to be adequately powered to detect a difference in the primary outcome of wound healing. Good practice guidelines should be followed for the design, implementation and reporting of any trial.
This review should be updated on the publication of the identified ongoing trial or on the publication of other randomised trials of test and treat strategies for elevated protease activity in venous leg ulcers.

\section{ACKNOWLEDGEMENTS}

The authors are grateful to the following peer reviewers for their time and comments: David Margolis, Gill Worthy, Georgina Gethin and Jane Nadel. The authors acknowledge the contribution of Megan Prictor and Elizabeth Royle, copy-editors.

\section{R E F E R E N C E S}

\section{References to studies excluded from this review}

\section{Cullen 2012 \{published data only\}}

Cullen B, Gibson M, Nisbet L. Targeted use of collagen/ ORC improves clinical outcomes. Wound Repair and Regeneration. Conference Publication. 22nd Annual Meeting of the European Tissue Repair Society. Athens, Greece, 2012:var.pagings A93.

Dompmartin 2007 \{published data only\} Dompmartin A, Schmutz JL, Collier M, Smith J, Bohbot $S$. Management of venous leg ulcers with two active wound dressings. Protocol of a randomized clinical trial. 17th Conference of the European Wound Management Association; 2007 2-4 May. Glasgow, Scotland, 2007:Oral presentation no 80,55 .

\section{Falabella 1998 \{published data only\}}

Falabella AF, Carson P, Eaglstein WH, Falanga V. The safety and efficacy of a proteolytic ointment in the treatment of chronic ulcers of the lower extremity. Journal of the American Academy of Dermatology 1998;39(5):737-40.

Gardner 2013 \{published data only\} Gardner S. Using treatment pathways to improve healing of venous leg ulceration. Wounds UK 2013;9(1):67-75.

Gravante 2013 \{published data only\}

Gravante G, Sorge R, Giordan N, Georgescu SR, Morariu $\mathrm{SH}$, Stoicescu I, et al. Multicenter clinical trial on the performance and tolerability of the hyaluronic acidcollagenase ointment for the treatment of chronic venous ulcers: a preliminary pilot study. European Review for Medical and Pharmacological Sciences 2013;17(20):2721-7.

Hodde 2006 \{published data only\}

Hodde JP, Hiles MC, Sillings N, Metzger DW.

Characterization of the local wound environment following treatment of chronic leg ulcers with SIS wound matrix. 19th Annual Symposium on Advanced Wound Care and 16th Medical Research Forum on Wounds; 2006 April 30May 3. San Antonio, Texas, 2006:Oral abstract 34.2 S187.
Humbert 2013 \{published data only\}

Humbert P, Faivre B, Veran Y, Debure C, Truchetet F, Becherel PA, et al. Protease-modulating polyacrylate-based hydrogel stimulates wound bed preparation in venous leg ulcers - A randomized controlled trial. Journal of the European Academy of Dermatology and Venereology 2013;28 (12):1742-50.

Karim 2006 \{published data only\} Karim RB, Brito BL, Dutrieux RP, Lassance FP, Hage JJ. MMP-2 assessment as an indicator of wound healing: a feasibility study. Advances in Skin and Wound Care 2006;19 (6):324-7.

Klemp 1986 \{published data only\} Klemp P, Staberg B, Ravnborg L. Local proteolytic treatment of infected varicose ulceration of the legs [Lokal proteolytisk behandling af inficeret åreknuder sårdannelse i benene]. Ugeskrift for Laeger 1986;148(13):760-2.

Manizate 2012 \{published data only\} Manizate F, Fuller A, Gendics C, Lantis JC. A prospective, single-center, nonblinded, comparative, postmarket clinical evaluation of a bovine-derived collagen with ionic silver dressing versus a carboxymethylcellulose and ionic silver dressing for the reduction of bioburden in variable-etiology, bilateral lower-extremity wounds. Advances in Skin and Wound Care 2012;25(5):220-5.

Metzner 1997 \{published data only\}

Metzner B, Vanscheidt W, Norgauer J. Influence of plateletderived products on mRNA expression of growth factors, inducible growth related genes, metalloproteinases and their inhibitors in ulcers of patients with chronic venous insufficiency. Australasian Journal of Dermatology 1997;38 Suppl 2:175.

\section{Moffatt 2014 \{published data only\}}

Moffatt CJ, Stanton J, Murray S, Doody V, Davis PJ, Franks PJ. A randomised trial to compare the performance of Oxyzyme and Iodozyme with standard care in the treatment of patients with venous and mixed venous/arterial ulceration. Wound Medicine 2014;6(1):1-10. 
O'Meara 2013a \{published data only\}

O’Meara S, Martyn-St James M. Foam dressings for venous leg ulcers. Cochrane Database of Systematic Reviews 2013, Issue 5. [DOI: 10.1002/14651858.CD009907.pub2]

Schmutz 2008 \{published data only\} Schmutz J-L, Meaume S, Fays S, Ourabah Z, Guillot $B$, Thirion V. Evaluation of the nano-oligosaccharide factor lipido-colloid matrix in the local management of venous leg ulcers: results of a randomised, controlled trial. International Wound Journal 2008;5(2):172-82.

Serra 2013 \{published data only\}

Serra R, Buffone G, Falcone D, Molinari V, Scaramuzzino $\mathrm{M}$, Gallelli L, et al. Chronic venous leg ulcers are associated with high levels of metalloproteinases- 9 and neutrophil gelatinase-associated lipocalin. Wound Repair and Regeneration 2013;21(3):395-401.

Serra 2014 \{published data only\}

Serra R, Gallelli L, Conti A, De Caridi G, Massara M, Spinelli F, et al. The effects of sulodexide on both clinical and molecular parameters in patients with mixed arterial and venous ulcers of lower limbs. Drug Design, Development and Therapy 2014;8:519-27.

Smeets 2008 \{published data only\}

Smeets R, Ulrich D, Unglaub F, Wöltje M, Pallua N. Effect of oxidised regenerated cellulose/collagen matrix on proteases in wound exudate of patients with chronic venous ulceration. International Wound Journal 2008;5(2): 195-203.

Smith 1994 \{published data only\}

Smith BA. The dressing makes the difference. Trial of two modern dressings on venous ulcers. Professional Nurse 1994; 5(348):350-2.

Stojadinovic 2014 \{published data only\}

Stojadinovic O, Ramirez H, Patel S, Yin N, Bollenbach $\mathrm{T}$, Golden P, et al. Genomic insight into molecular mechanisms of action of bilayered living cellular construct nonhealing venous leg ulcers. Wound Repair and Regeneration. Conference Publication; 24th Annual Meeting of the Wound Healing Society; SAWC-Spring/ WHS Joint Meeting. Orlando, FL United States, 2014: var.pagings A60.

Tang 2012 \{published data only\}

Tang JC, Marston WA, Kirsner RS. Wound Healing Society (WHS) venous ulcer treatment guidelines: what's new in five years?. Wound Repair and Regeneration 2012;20(5): 619-37.

Varelias 2002 \{published data only\}

Varelias A, Hughes H, Cowin A, Cowled P, Cooter R, Harries R, et al. Detection and modulation of matrix metalloproteinases in patients with chronic leg ulcers treated with whey-derived growth factors. Fourth Australian Wound Management Association Conference; 2002; 7-10 March. 2002.

Varelias 2006 \{published data only\}

Varelias A, Cowin AJ, Adams D, Harries RHC, Cooter RD, Belford DA, et al. Mitogenic bovine whey extract modulates matrix metalloproteinase-2, -9 , and tissue inhibitor of matrix metalloproteinase-2 levels in chronic leg ulcers. Wound Repair and Regeneration 2006;14(1):28-37.

\section{References to ongoing studies}

\section{NCT 01537003 \{published data only (unpublished sought but not used)\}}

NCT 01537003. WOUNDCHEK ${ }^{\mathrm{TM}}$ protease status point of care (POC) diagnostic test. https://clinicaltrials.gov/ct2/ show/NCT01537003 2012; (Verified May 2013; Accessed May 2015).

\section{Additional references}

\section{AHRQ 2012}

Agency for Healthcare Research and Quality (AHRQ), Chang SM, Matchar DB (Eds). Methods Guide for Medical Test Reviews. Vol. AHRQ Publication No. 12-EHC017, Rockville, MD: Agency for Healthcare Research and Quality (AHRQ), 2012.

\section{Andriessen 2009}

Andriessen A, Polignano R, Abel M. Monitoring the microcirculation to evaluate dressing performance in patients with venous leg ulcers. Journal of Wound Care 2009;18(4):148-50.

\section{Anichini 2013}

Anichini R, Tedeschi A, Bernini A, Barbanera L, De Bellis A. Detecting and treating Elevated Protease Activity (EPA) in chronic diabetic wounds. EWMA Journal 2013;13(1 Suppl 1):275, abstract no 479.

Ashby 2014

Ashby RL, Gabe R, Ali S, Adderly U. Clinical and costeffectiveness of compression hosiery versus compression bandages in treatment of venous leg ulcers (Venous leg Ulcer Study IV, VenUS IV): a randomised controlled trial. Lancet 2014;383:871-9.

\section{Augustin 2012}

Augustin M, Brocatti LK, Rustenbach SJ, Schafer I, Herberger K. Cost-of-illness of leg ulcers in the community. International Wound Journal 2012;11(3):283-92.

\section{Barrett 2011}

Barrett S, Davis L, Edwards J, Fletcher J, Harding K, Jack $\mathrm{L}$, et al. Protease diagnostic in wound care: round-table meeting. Wounds UK 2011;4(4 Suppl 1).

\section{BNF 2015}

British National Formulary, British Medical Association, British Royal Pharmaceutical Society of Great Britain. British National Formulary. London: British Medical Association, 2015.

\section{Bossuyt 2009}

Bossuyt PMM, McCaffery K. Additional patient outcomes and pathways in evaluations of testing. Medical Decision Making 2009;29(5):E30-8.

\section{Bouza 2005}

Bouza C, Munoz A, Amate JM. Efficacy of modern dressings in the treatment of leg ulcers: a systematic review. Wound Repair and Regeneration 2005;13(3):218-29. 


\section{Callam 1987}

Callam MJ, Harper DR, Dale JJ, Ruckley CV. Chronic ulcer of the leg: clinical history. BMJ 1987;294(6584): 1389-91.

Chin 2003

Chin GA, Thigpin TG, Perrin KJ, Moldawer LL, Schulz GS. Treatment of chronic ulcers in diabetic patients with a topical metalloproteinase inhibitor, doxycycline. Wounds 2003;15:315-23.

\section{Coleridge Smith 1988}

Coleridge Smith PD, Thomas P, Scurr JH, Dormandy JA. Causes of venous ulceration: a new hypothesis. BMJ 1988; 296(6638): 1726-7.

\section{Cullen 2002}

Cullen B, Smith R, McCulloch E, Silcock D, Morrisson L. Mechanism of action of PROMOGRAN, a protease modulating matrix, for the treatment of diabetic foot ulcers. Wound Repair and Regeneration 2002;10(1):16-25.

\section{Cullen 2011}

Cullen B, Gibson M, Nesbit L. Targeted use of protease modulating dressings improves clinical outcomes. Wounds UK, Harrogate. 2011:Poster.

\section{Deeks 2011}

Deeks JJ, Higgins JPT, Altman DG (editors). Chapter 9: Analysing data and undertaking meta-analyses. In: Higgins JPT, Green S (editors). Cochrane Handbook for Systematic Reviews of Interventions. Version 5.1.0 [updated March 2011]. The Cochrane Collaboration, 2011. Available from www.cochrane-handbook.org. The Cochrane Collaboration.

\section{Dumville 2009}

Dumville JC, Worthy G, Soares MO, Bland JM. VenUS II: a randomised controlled trial of larval therapy in the management of leg ulcers. Health Technology Assessment 2009; 13(55):1-206.

\section{Ferrante di Ruffano 2012}

Ferrante di Ruffano L, Hyde CJ, McCaffery KJ, Bossuyt PMM, Deeks JJ. Assessing the value of diagnostic tests: a framework for designing and evaluating trials. BMJ 2012; 344:e686. [DOI: http://dx.doi.org/10.1136/bmj.e686]

\section{Fryback 1991}

Fryback DG, Thornbury JR. The efficacy of diagnostic imaging. Medical Decision Making 1991;11(2):88-94.

Ghauri 2010

Ghauri ASK, Nyamekye IK. Leg ulceration: the importance of treating the underlying pathophysiology. Phlebology / Venous Forum of the Royal Society of Medicine 2010;25(S1): $42-51$.

Gohel 2005

Gohel MS, Taylor M, Earnshaw JJ, Heather BP, Poskitt KR, Whyman MR. Risk factors for delayed healing and recurrence of chronic venous leg ulcers - an analysis of 1324 legs. European Journal of Vascular and Endovascular Surgery 2005;29(1):74-7.

\section{Gohel 2007}

Gohel MS, Barwell JR, Taylor M, Chant T, Foy C, Earnshaw JJ, et al. Long term results of compression therapy alone versus compression plus surgery in chronic venous ulceration (ESCHAR): randomised controlled trial. BMJ 2007;335(7610):83-7.

Graham 2003

Graham ID, Harrison MB, Nelson EA, Lorimer K, Fisher A. Prevalence of lower-limb ulceration: a systematic review of prevalence studies. Advances in Skin and Wound Care 2003;16(6):305-16.

\section{Greer 2013}

Greer N, Foman NA, MacDonald R, Dorrian J, Fitzgerald P, Rutks I, et al. Advanced wound care therapies for nonhealing diabetic, venous, and arterial ulcers: a systematic review. Annals of Internal Medicine 2013;159(8):532-42.

\section{Guyatt 1986}

Guyatt GH, Tugwell PX, Feeny DH, Haynes RB, Drummond M. A framework for clinical evaluation of diagnostic technologies. Canadian Medical Association Journal 1986;134:587-94.

\section{Hahn 2005}

Hahn S, Puffer S, Torgerson DJ, Watson J. Methodological bias in cluster randomised trials. BMC Medical Research Methodology 2005; Vol. 5, issue 10. [DOI: 10.1186/ 1471-2288-5-10]

Hall 2014

Hall J, Buckley HL, Lamb KA, Stubbs N, Saramago P, Dumville JC, et al. Point prevalence of complex wounds in a defined United Kingdom population. Wound Repair and Regeneration 2014;22(6):694-700.

\section{Herber 2007}

Herber OR, Schnepp W, Rieger MA. A systematic review on the impact of leg ulceration on patients' quality of life. Health and Quality of Life Outcomes 2007;5:44. [DOI: $10.1186 / 1477-7525-5-44]$

Higgins 2003

Higgins JPT, Thompson SG, Deeks JJ, Altman DG. Measuring inconsistency in meta-analyses. BMJ 2003;327 (7414):557-60.

\section{Higgins 2011a}

Higgins JPT, Altman DG, Sterne JAC (editors). Chapter 8: Assessing risk of bias in included studies. In: Higgins JPT, Green S (editors). Cochrane Handbook for Systematic Reviews of Interventions. Version 5.1.0 [updated March 2011]. The Cochrane Collaboration, 2011. Available from: www.cochrane-handbook.org. The Cochrane Collaboration.

\section{Higgins 2011b}

Higgins JPT, Deeks JJ, Altman DG (editors). Chapter 16: Special topics in statistics. In: Higgins JPT, Green S (editors). Cochrane Handbook for Systematic Reviews of Interventions. Version 5.1.0 [updated March 2011]. The Cochrane Collaboration, 2011. Available from www.cochrane-handbook.org. The Cochrane Collaboration. 


\section{International Consensus 2011}

Harding KG (ed), International Consensus Expert Working Group. International consensus. The role of proteases in wound diagnostics. An expert working group review. London: Wounds International, 2011.

\section{Johnson 1995}

Johnson M. The prevalence of leg ulcers in older people: implications for community nursing. Public Health Nursing 1995;12(4):269-75.

\section{Jull 2012}

Jull AB, Arroll B, Parag V, Waters J. Pentoxifylline for treating venous leg ulcers. Cochrane Database of Systematic Reviews 2012, Issue 12. [DOI: 10.1002/ 14651858.CD001733.pub3]

Kakagia 2007

Kakagia DD, Kazakos KJ, Xarchas KC, Karanikas M, Georgiadis GS, Tripsiannis G, et al. Synergistic action of protease-modulating matrix and autologous growth factors in healing of diabetic foot ulcers. A prospective randomized trial. Journal of Diabetes and its Complications 2007;21(6): 387-91.

\section{Kantor 2000}

Kantor J, Margolis DJ. A multicentre study of percentage change in venous leg ulcer area as a prognostic index of healing at 24 weeks. British Journal of Dermatology 2000; 142(5):960-4.

\section{Kontopantelis 2012}

Kontopantelis E, Reeves D. Performance of statistical methods for meta-analysis when true study effects are nonnormally distributed: a simulation study. Statistical Methods in Medical Research 2012;21(4):409-26.

\section{Kontopantelis 2013}

Kontopantelis E, Springate DA, Reeves D. A re-analysis of the Cochrane Library data: the dangers of unobserved heterogeneity in meta-analyses. PLoS One 2013;26:e69930.

\section{Ladwig 2002}

Ladwig GP, Robson MC, Liu R, Kuhn MA, Muir DF, Schultz GS. Ratios of activated matrix metalloproteinase-9 to tissue inhibitor of matrix metalloproteinase-1 in wound fluids are inversely correlated with healing of pressure ulcers. Wound Repair and Regeneration 2002;10(1):26-37.

\section{Lefebvre 2011}

Lefebvre C, Manheimer E, Glanville J. Chapter 6: Searching for studies. In: Higgins JPT, Green S (editors). Cochrane Handbook for Systematic Reviews of Interventions. Version 5.1.0 [updated March 2011]. The Cochrane Collaboration, 2011. Available from www.cochrane-handbook.org. The Cochrane Collaboration.

\section{Liberati 2009}

Liberati A, Altman DG, Tetzlaff J, Mulrow C, Gotzsche PC, Ioannidis JP, et al. The PRISMA statement for reporting systematic reviews and meta-analyses of studies that evaluate health care interventions: explanation and elaboration. PLoS Medicine 2009;6:e1000100.
Liu 2009

Liu Y, Min D, Bolton T, Nube V, Twigg SM, Yue DK, et al. Increased matrix metalloproteinase-9 predicts poor wound healing in diabetic foot ulcers. Diabetes Care 2009;32(1): 117-9.

Lobmann 2006

Lobmann R, Zemlin C, Motzkau M, Rescke K, Lehnert H. Expression of matrix metalloproteinases and growth factors in diabetic foot wounds treated with a protease absorbent dressing. Journal of Diabetes and its Complications 2006;20 (5):329-35.

\section{Lord 2006}

Lord SJ, Irwig L, Simes RJ. When is measuring sensitivity and specificity sufficient to evaluate a diagnostic test, and when do we need randomized trials?. Annals of Internal Medicine 2006;144:850-5.

Lord 2009

Lord SJ, Irwig L, Bossuyt PMM. Using the principles of randomized controlled trial design to guide test evaluation. Medical Decision Making 2009;29(5):E1-12.

\section{Madden 2014}

Madden M. Is research in chronic wound care focusing on the outcomes that matter most to patients?. BSA Annual Conference. 2014; Vol. Changing Society.

\section{Margolis 2004}

Margolis DJ, Allen-Taylor L, Hoffstad O, Berlin JA. The accuracy of venous leg ulcer prognostic models in a wound care system. Wound Repair and Regeneration 2004;12(2): 163-8.

McCarty 2013 McCarty SM, Percival SL. Proteases and delayed wound healing. Advances in Wound Care 2013;2(8):438-47.

\section{Moffatt 2004}

Moffatt CJ, Franks PJ, Doherty DC, Martin R, Blewett R, Ross F. Prevalence of leg ulceration in a London population. QJM: Monthly Journal of the Association of Physicians 2004; 97(7):431-7.

Mwaura 2006 Mwaura B, Mahendran B, Hynes N, Defreitas D, Avalos G, Adegbola T, et al. The impact of differential expression of extracellular matrix metalloproteinase inducer, matrix metalloproteinase-2, tissue inhibitor of matrix metalloproteinase-2 and PDGF-AA on the chronicity of venous leg ulcers. European Journal of Vascular and Endovascular Surgery 2006;31(3):306-10.

\section{Nelson 2014}

Nelson EA, Hillman A, Thomas K. Intermittent pneumatic compression for treating venous leg ulcers. Cochrane Database of Systematic Reviews 2014, Issue 5. [DOI: 10.1002/14651858.CD001899.pub4]

\section{Nelzen 1994}

Nelzen O, Berqvist D, Lindhagen A. Venous and nonvenous leg ulcers: clinical history and appearance in a population study. British Journal of Surgery 1994;81:182-7. 
Nelzen 1997

Nelzen O, Bergqvist D, Lindhagen A. Long-term prognosis for patients with chronic leg ulcers: a prospective cohort study. European Journal of Vascular and Endovascular Surgery 1997;15:500-8.

\section{Nelzen 2008}

Nelzen O. Prevalence of venous leg ulcer: the importance of the data collection method. Phlebolymphology 2008;15(4): $143-50$.

NICE 2012

National Institute for Health and Clinical Excellence (NICE). The Guidelines Manual. Available from www.nice.org.uk. Accessed June 2015. London: National Institute for Health and Clinical Excellence, 2012.

\section{NICE 2015}

National Institute for Health and Care Excellence. Clinical knowledge summaries. Leg ulcer - venous. http:// cks.nice.org.uk/leg-ulcer-venous\#!topic summary. Last revised April 2015. Accessed June 2015.

\section{Nisi 2005}

Nisi G, Brandi C, Grimaldi L, Calabro M, D'Aniello C. Use of a protease-modulating matrix in the treatment of pressure sores. Chirugia Italiana 2005;57(4):465-8.

\section{Nwomeh 1998}

Nwomeh BC, Liang HX, Diegelmann RF, Cohen IK, Yager DR. Dynamics of the matrix metalloproteinases MMP-1 and MMP-8 in acute open human dermal wounds. Wound Repair and Regeneration 1998;6(2):127-34.

Nwomeh 1999

Nwomeh BC, Liang HX, Cohen IK, Yager DR. MMP8 is the predominant collagenase in healing wounds and nonhealing ulcers. Journal of Surgical Research 1999;81(2): $189-95$.

\section{O'Donnell 2006}

O'Donnell JR, Lau J. A systematic review of randomized controlled trials of wound dressings for chronic venous ulcer. Journal of Vascular Surgery 2006;44(5):1118-25.

\section{O'Meara 2012}

O'Meara S, Cullum N, Nelson EA, Dumville JC. Compression for venous leg ulcers. Cochrane Database of Systematic Reviews 2012, Issue 11. [DOI: 10.1002/ 14651858.CD000265.pub3]

\section{O'Meara 2013b}

O'Meara S, Martyn-St James M. Alginate dressings for venous leg ulcers. Cochrane Database of Systematic Reviews 2013, Issue 4. [DOI: 10.1002/14651858.CD010182.pub2]

\section{O'Meara 2014}

O’Meara S, Al-Kurdi D, Ologun Y, Ovington LG, Martyn-StJames M, Richardson R. Antibiotics and antiseptics for venous leg ulcers. Cochrane Database of Systematic Reviews 2014, Issue 1. [DOI: 10.1002/ 14651858.CD003557.pub5]

\section{Parmar 1998}

Parmar MKB, Torri V, Stewart L. Extracting summary statistics to perform meta-analyses of the published literature for survival endpoints. Statistics in Medicine 1998; 17:2815-34.

\section{Persoon 2004}

Persoon A, Heinen MM, van der Vleuten CJM, de Rooji MJ, van de Kerkhof PCM, van Achterberg T. Leg ulcers: a review of their impact on daily life. Journal of Clinical Nursing 2004;13(3):341-54.

\section{Ragnarson Tennvall 2005}

Ragnarson Tennvall G, Hjelmgren J. Annual costs of treatment for venous leg ulcers in Sweden and the United Kingdom. Wound Repair and Regeneration 2005;13(1): $13-18$.

\section{RCN 2006}

Royal College of Nursing. The nursing management of patients with venous leg ulcers: recommendations. http: //www.rcn.org.uk/ ' data/assets/pdf' file/0003/107940/ 003020.pdf 2006. Accessed November 2014.

Rector 2012

Rector TS, Taylor BC, Wilt TJ. Chapter 12: Systematic review of prognostic tests. Methods Guide for Medical Test Reviews (AHRQ Publication No. 12-EHC017). Rockville,

MD. Available at www .effectivehealthcare .ahrq.gov/ reports/final.cfm: Agency for Healthcare Research and Quality (AHRQ), 2012.

\section{RevMan 2014 [Computer program]}

The Nordic Cochrane Centre, The Cochrane Collaboration. Review Manager (RevMan). Version 5.3. Copenhagen: The Nordic Cochrane Centre, The Cochrane Collaboration, 2014.

Robson 2006

Robson MC, Cooper DM, Aslam R, Gould LJ, Harding $\mathrm{KG}$, Margolis DJ, et al. Guidelines for the treatment of venous ulcers. Wound Repair and Regeneration 2006;14(6): 649-62.

\section{Schünemann 2011a}

Schünemann HJ, Oxman AD, Higgins JPT, Deeks JJ, Glasziou P, Guyatt GH. Chapter 12: Interpreting results and drawing conclusions. In: Higgins JPT, Green $S$ (editors). Cochrane Handbook for Systematic Reviews of Interventions. Version 5.1.0 [updated March 2011]. The Cochrane Collaboration, 2011. Available from www.cochrane-handbook.org. Version 5.1.0 [updated March 2011]. The Cochrane Collaboration.

\section{Schünemann 2011b}

Schünemann HJ, Oxman AD, Higgins JPT, Vist GE, Glasziou P, Guyatt GH. Chapter 11: Presenting results and 'Summary of findings' tables. In: Higgins JPT, Green $S$ (editors). Cochrane Handbook for Systematic Reviews of Interventions. Version 5.1.0 [updated March 2011]. The Cochrane Collaboration, 2011. Available from www.cochrane-handbook.org. Version 5.1.0 [updated March 2011]. The Cochrane Collaboration.

Serena 2011

Serena T, Cullen B, Bayliff S, Gibson M, DeMarco D, Galbraith J, et al. Protease activity levels associated with 
healing status of chronic wounds. Wounds UK (Harrogate). 2011:Poster.

\section{Sibbald 2012}

Sibbald RG, Snyder RJ, Botros M, Burrows C, Coutts P, D'Souza L, et al. Role of a point-of-care protease activity diagnostic test in Canadian clinical practice: a Canadian expert consensus. Advances in Skin and Wound Care 2012; 25(6):267-75.

\section{SIGN 2010}

Scottish Intercollegiate Guidelines Network (SIGN). Management of chronic venous leg ulcers. Edinburgh: Scottish Intercollegiate Guidelines Network, Healthcare Improvement Scotland, 2010; Vol. 120.

\section{SIGN 2011}

Scottish Intercollegiate Guidelines Network (SIGN). Search filters. http://www.sign.ac.uk/methodology/filters.html\# random (accessed December 2011).

\section{Snyder 2011}

Snyder RJ, Driver V, Fife CE, Lantis J, Peirce B, Serena T, et al. Using a diagnostic tool to identify elevated protease activity levels in chronic and stalled wounds: a consensus panel discussion. Ostomy Wound Management 2011;57(12): $36-46$.

Snyder 2012

Snyder RJ, Cullen B, Nisbet LT. An audit to assess the perspectives of US wound care specialists regarding the importance of proteases in wound healing and wound assessment. International Wound Journal 2012;10(6): 653-60.

Srinivasaiah 2007

Srinivasaiah N, Dugdall H, Barrett S, Drew PJ. A point prevalence survey of wounds in north-east England. Journal of Wound Care 2007;16(10):413-9.

Sterne 2011

Sterne JAC, Egger M, Moher D. Chapter 10: Addressing reporting biases. In: Higgins JPT, Green S (editors). Cochrane Handbook for Systematic Reviews of Interventions. Version 5.1.0 [updated March 2011]. The Cochrane Collaboration, 2011. Available from www.cochrane-handbook.org. Version 5.1.0 [updated March 2011]. The Cochrane Collaboration.

Systagenix 2013

Systagenix. WOUNDCHEK TM Protease Status. http://www.systagenix.co.uk/our-products/lets-test/ woundchekandtrade-protease-status-218. 2013 (accessed November 2014).

\section{Thompson 1999}

Thompson SG, Sharp SJ. Explaining heterogeneity in metaanalysis: a comparison of methods. Statistics in Medicine 1999; 18:2693-708.

\section{Thompson 2002}

Thompson SG, Higgins JPT. How should meta-regression analyses be undertaken and interpreted?. Statistics in Medicine 2002;21:1559-74.
Tierney 2007

Tierney JF, Stewart LA, Ghersi D, Burdett S, Sydes MR. Practical methods for incorporating summary time-to-event data into meta-analysis. Trials 2007;7(8):16.

\section{Trengove 1999}

Trengove NJ, Stacey MC, MacAuley S, Bennett N, Gibson $\mathrm{J}$, Burslem F, et al. Analysis of the acute and chronic wound environments: the role of proteases and their inhibitors. Wound Repair and Regeneration 1999;7(6):442-52.

Valencia 2001

Valencia IC, Falabella A, Kirsner RS, Eaglestein WH. Chronic venous insufficiency and venous leg ulceration. Journal of the American Academy of Dermatology 2001;44: $401-21$.

Veves 2002

Veves A, Sheehan P, Hau T, Pham DPM. Promogram Diabetic Foot Ulcer Study. A randomized controlled trial of Promogram (a collagen/oxidised regenerated cellulose dressing) vs standard treatment in the management of diabetic foot ulcers. Archives of Surgery 2002;137(7):822-7.

\section{Vowden 2009a}

Vowden KR, Vowden P. The prevalence, management and outcome for patients with lower limb ulceration identified in a wound care survey within one English health care district. Journal of Tissue Viability 2009;18(1):13-19.

\section{Vowden 2009b}

Vowden K, Vowden P. The resource costs of wound care in Bradford and Airedale primary care trust in the UK. Journal of Wound Care 2009;18(3):93-102.

\section{Walker 2002}

Walker N, Rodgers A, Birchall N, Norton R, MacMahon $\mathrm{S}$. The occurrence of leg ulcers in Auckland: results of a population-based survey. New Zealand Medical Journal 2002;115(1151):159-62.

\section{Westby 2015}

Westby MJ, Dumville JC, Stubbs N, Norman G, Cullum $\mathrm{N}$. Protease-modulating matrix treatments for healing venous leg ulcers. Cochrane Database of Systematic Reviews 2015, Issue 10. [DOI: 10.1002/14651858.CD011918]

Woo 2013

Woo KY, Alavi A, Evans R, Despatis M, Allen J. New advances in compression therapy for venous leg ulcers. Surgical Technology International 2013;23:61-8.

\section{Wound Care Handbook} Journal of Wound Care. Wound Care Handbook. http:// www.woundcarehandbook.com/ Accessed February 2015.

\section{Yaffe 2012}

Yaffe J, Montgomery P, Hopewell S, Shepard LD. Empty reviews: a description and consideration of Cochrane systematic reviews with no included studies. PLoS One 2012;7(5):E36626.

\section{Yager 2002}

Yager DR, Nwomeh BC. The proteolytic environment of chronic wounds. Wound Repair and Regeneration 2002;7(6): 433-41. 
References to other published versions of this review

Norman 2015

Norman G, Westby MJ, Stubbs N, Dumville JC, Cullum

N. A 'test and treat' strategy for elevated wound protease activity for healing in venous leg ulcers. Cochrane Database of Systematic Reviews 2015, Issue 6. [DOI: 10.1002/ 14651858.CD011753]

* Indicates the major publication for the study 


\section{CHARACTERISTICS OF STUDIES}

\section{Characteristics of excluded studies [ordered by study ID]}

\begin{tabular}{|c|c|}
\hline Study & Reason for exclusion \\
\hline Cullen 2012 & Does not evaluate a test and treat strategy; test used but not the basis for treatment decisions \\
\hline Dompmartin 2007 & Does not evaluate a test and treat strategy \\
\hline Falabella 1998 & Wrong intervention: does not evaluate a protease-modulating intervention \\
\hline Gardner 2013 & Not a randomised controlled trial \\
\hline Gravante 2013 & Wrong intervention: does not evaluate a protease-modulating intervention \\
\hline Hodde 2006 & Not a randomised controlled trial \\
\hline Humbert 2013 & Does not evaluate a test and treat strategy \\
\hline Karim 2006 & Not a randomised controlled trial \\
\hline Klemp 1986 & Not a randomised controlled trial (review) \\
\hline Manizate 2012 & Does not evaluate a test and treat strategy \\
\hline Metzner 1997 & Not a randomised controlled trial \\
\hline Moffatt 2014 & Does not evaluate a test and treat strategy \\
\hline O’Meara 2013a & Not a randomised controlled trial (systematic review) \\
\hline Schmutz 2008 & Does not evaluate a test and treat strategy \\
\hline Serra 2013 & Not a randomised controlled trial \\
\hline Serra 2014 & Wrong intervention: does not evaluate a protease-modulating intervention \\
\hline Smeets 2008 & Does not evaluate a test and treat strategy \\
\hline Smith 1994 & Wrong intervention: does not evaluate a protease-modulating intervention \\
\hline Stojadinovic 2014 & Does not evaluate a test and treat strategy \\
\hline Tang 2012 & Not a randomised controlled trial (review) \\
\hline Varelias 2002 & Wrong intervention: does not evaluate a protease-modulating intervention \\
\hline
\end{tabular}


Characteristics of ongoing studies [ordered by study ID]

\section{NCT 01537003}

\begin{tabular}{ll} 
Trial name or title & WOUNDCHEKTM Protease Status Point of Care (POC) Diagnostic Test \\
\hline Methods & $\begin{array}{l}\text { Randomised controlled trial } \\
\text { Open label efficacy study } \\
\text { Primary purpose diagnostic }\end{array}$ \\
\hline Participants & $\begin{array}{l}\text { Adults (aged at least } 18 \text { years) with venous leg ulcers (ABPI } \geq 0.8 \text { ) willing/able to use appropriate compression } \\
\text { therapy. Ulcers with a duration between } 6 \text { weeks and } 3 \text { years and area between } 1 \mathrm{~cm}^{2} \text { and } 100 \mathrm{~cm}^{2} \text { (maximum } \\
\text { length } 10 \mathrm{~cm}) . \text { Ulcers needed to show no signs of local or systemic infection; C-reactive protein needed to be } \\
\text { normal and leukocyte levels below } 10,000 \text {. Wounds could not be treated with PROMOGRAN dressing in } \\
\text { the } 4 \text { weeks prior to study entry } \\
\text { Exclusion criteria: known hypersensitivity to wound dressings used; local or systemic antibiotics in week prior } \\
\text { to inclusion; cancer treated by radiotherapy or chemotherapy; prolonged treatment with immunosuppressive } \\
\text { agents/high dose corticosteroids; current illness or condition which may interfere with wound healing in } \\
\text { the last } 30 \text { days (carcinoma, connective tissue disease, autoimmune disease or alcohol or drug abuse); life } \\
\text { expectancy of }<6 \text { months; uncontrolled diabetes; participation in a clinical trial on wound healing within } \\
\text { the past month; unable to understand aims and objectives of the trial; known history of non-adherence with } \\
\text { medical treatment; pregnancy; HIV/AIDS; viral hepatitis }\end{array}$
\end{tabular}

Interventions $\quad$ Patients with low EPA: Collagen/ORC dressing (PROMOGRAN®) plus 2 layer compression bandage Patients with low EPA: 2 layer compression bandage only Patients with high EPA: Collagen/ORC dressing (PROMOGRAN®) plus 2 layer compression bandage Patients with high EPA: 2 layer compression bandage only

Primary outcomes
- Identification of wounds with elevated protease activity (EPA) and comparison of the healing
outcomes of two treatment regimes (collagen/ORC (PROMOGRAN®), a protease-modulating therapy
versus current standard of care) on chronic wounds with EPA.
- Improved healing outcome defined as the proportion of wounds which reach a minimum $30 \%$
percentage reduction in wound surface area over a four-week treatment period.
Secondary outcomes
- The average percentage change in protease activity levels pre- and post-treatment (12 weeks).
- The proportion of wounds achieving wound closure (defined as a restoration of a complete epithelial
cover) at 12 weeks.
- The average time to wound closure.
- The relative cost effectiveness of both treatment regimes when they are targeted appropriately.

Starting date $\quad$ October 2012

Contact information Breda Cullen, PhD, Systagenix Wound Management 


\section{NCT 01537003 (Continued)}




\section{DATA ANDANALYSES}

This review has no analyses.

\section{A P P E N D I C E S}

\section{Appendix I. Search strategies for MEDLINE, EMBASE \& CINAHL MEDLINE}

1 exp Leg Ulcer/

2 (varicose ulcer* or venous ulcer* or leg ulcer* or stasis ulcer* or crural ulcer* or ulcus cruris or ulcer cruris).tw.

3 or/1-2

4 exp Peptide Hydrolases/

5 (protease* or proteinase* or metalloproteinase* or peptidase* or "peptide hydrolase" or "peptide hydrolases" or "proteolytic enzymes"

or "proteolytic enzyme" or esteroprotease*).tw.

6 or $/ 4-5$

7 and $/ 3,6$

8 randomized controlled trial.pt.

9 controlled clinical trial.pt.

10 randomi?ed.ab.

11 placebo.ab.

12 clinical trials as topic.sh.

13 randomly.ab.

14 trial.ti.

15 or/8-14

16 exp animals/ not humans.sh.

1715 not 16

187 and 17

EMBASE

1 leg ulcer/ or foot ulcer/ or leg varicosis/

2 (varicose ulcer* or venous ulcer* or leg ulcer* or stasis ulcer* ${ }^{*}$ or crural ulcer* or ulcus cruris or ulcer cruris).tw.

3 or/ $1-2$

4 exp proteinase/

5 (protease* or proteinase* or metalloproteinase* or peptidase* or "peptide hydrolase" or "peptide hydrolases" or "proteolytic enzymes" or "proteolytic enzyme" or esteroprotease*).tw.

6 or/ $4-5$

7 and $/ 3,6$

8 Randomized controlled trials/

9 Single-Blind Method/

10 Double-Blind Method/

11 Crossover Procedure/

12 (random $\$$ or factorial\$ or crossover $\$$ or cross over $\$$ or cross-over $\$$ or placebo $\$$ or assign $\$$ or allocat $\$$ or volunteer $\$$ ).ti,ab.

13 (doubl\$ adj blind\$).ti,ab.

14 (singl\$ adj blind\$).ti,ab.

15 or/8-14

16 exp animals/ or exp invertebrate/ or animal experiment/ or animal model/ or animal tissue/ or animal cell/ or nonhuman/

17 human/ or human cell/

18 and/16-17

1916 not 18

A 'test and treat' strategy for elevated wound protease activity for healing in venous leg ulcers (Review)

Copyright $\odot 2016$ The Cochrane Collaboration. Published by John Wiley \& Sons, Ltd. 
2015 not 19

21 Randomized controlled trials/

22 Single-Blind Method/

23 Double-Blind Method/

24 Crossover Procedure/

25 (random\$ or factorial\$ or crossover $\$$ or cross over $\$$ or cross-over $\$$ or placebo $\$$ or assign $\$$ or allocat $\$$ or volunteer\$).ti,ab.

26 (doubl\$ adj blind\$).ti,ab.

27 (singl\$ adj blind\$).ti,ab.

28 or/ $21-27$

29 exp animals/ or exp invertebrate/ or animal experiment/ or animal model/ or animal tissue/ or animal cell/ or nonhuman/

30 human/ or human cell/

31 and $/ 29-30$

3229 not 31

3328 not 32

347 and 33

CINAHL

S1 MH "Leg Ulcer+"

S2 TI ( (varicose ulcer* or venous ulcer* or leg ulcer* or stasis ulcer* or crural ulcer* or ulcus cruris or ulcer cruris) ) OR AB ( (varicose ulcer* or venous ulcer* or leg ulcer* or stasis ulcer* or crural ulcer* or ulcus cruris or ulcer cruris) )

S3 S1 OR S2

S4(MH "Peptide Hydrolases+")

S5 TX (protease* or proteinase* or metalloproteinase* or peptidase* or "peptide hydrolase" or "peptide hydrolases" or "proteolytic enzymes" or "proteolytic enzyme" or esteroprotease*)

S6 S4 OR S5

S7 S3 AND S6

S8 MH "Clinical Trials+"

S9 PT Clinical trial

S10 TI clinic* N1 trial* or AB clinic* N1 trial*

S11TI ( singl* or doubl* or trebl* or tripl* ) and TI ( blind* or mask* )

S12 AB ( singl* or doubl* or trebl* or tripl* ${ }^{*}$ ) and AB (blind* or mask* )

S13 TI randomi?ed control* trial* $^{*}$ or $\mathrm{AB}$ randomi?ed control* trial $^{*}$

S14 MH "Random Assignment"

S15 TI random* allocat* or AB random* allocat*

S16 MH "Placebos"

S17 TI placebo* or AB placebo*

S18 MH "Quantitative Studies"

S19 S8 or S9 or $S 10$ or $S 11$ or $S 12$ or $S 13$ or $S 14$ or $S 15$ or $S 16$ or $S 17$ or $S 18$

S20 S7 AND S19

\section{Appendix 2. Assessment of risk of bias}

1. Was the allocation sequence randomly generated?

Low risk of bias

The investigators describe a random component in the sequence generation process such as: referring to a random-number table; using a computer random-number generator; coin tossing; shuffling cards or envelopes; throwing dice; drawing of lots.

\section{High risk of bias}

The investigators describe a non-random component in the sequence generation process. Usually, the description would involve some systematic, non-random approach, for example: sequence generated by odd or even date of birth; sequence generated by some rule based on date (or day) of admission; sequence generated by some rule based on hospital or clinic record number.

Unclear

Insufficient information about the sequence generation process provided to permit a judgement of low or high risk of bias.

2. Was the treatment allocation adequately concealed?

A 'test and treat' strategy for elevated wound protease activity for healing in venous leg ulcers (Review)

Copyright $\odot 2016$ The Cochrane Collaboration. Published by John Wiley \& Sons, Ltd. 


\section{Low risk of bias}

Participants and investigators enrolling participants could not foresee assignment because one of the following, or an equivalent method, was used to conceal allocation: central allocation (including telephone, web-based and pharmacy-controlled randomisation); sequentially-numbered drug containers of identical appearance; sequentially-numbered, opaque, sealed envelopes.

\section{High risk of bias}

Participants or investigators enrolling participants could possibly foresee assignments and thus introduce selection bias, such as allocation based on: using an open random allocation schedule (e.g. a list of random numbers); assignment envelopes were used without appropriate safeguards (e.g. if envelopes were unsealed or non-opaque or not sequentially numbered); alternation or rotation; date of birth; case record number; any other explicitly unconcealed procedure.

\section{Unclear}

Insufficient information provided to permit a judgement of low or high risk of bias. This is usually the case if the method of concealment is not described or not described in sufficient detail to allow a definite judgement, for example if the use of assignment envelopes is described, but it remains unclear whether envelopes were sequentially numbered, opaque and sealed.

\section{Blinding - was knowledge of the allocated interventions adequately prevented during the study?}

\section{Low risk of bias}

Any one of the following.

- No blinding, but the review authors judge that the outcome and the outcome measurement are not likely to be influenced by lack of blinding.

- Blinding of participants and key study personnel ensured, and unlikely that the blinding could have been broken.

- Either participants or some key study personnel were not blinded, but outcome assessment was blinded and the non-blinding of others was unlikely to introduce bias.

\section{High risk of bias}

Any one of the following.

- No blinding or incomplete blinding, and the outcome or outcome measurement is likely to be influenced by lack of blinding.

- Blinding of key study participants and personnel attempted, but likely that the blinding could have been broken and the outcome or outcome measurement is likely to be influenced by lack of blinding.

- Either participants or some key study personnel were not blinded, and the non-blinding was likely to introduce bias.

Unclear

Either of the following.

- Insufficient information provided to permit a judgement of low or high risk of bias.

- The study did not address this outcome.

\section{Were incomplete outcome data adequately addressed?}

\section{Low risk of bias}

Any one of the following.

- No missing outcome data.

- Reasons for missing outcome data unlikely to be related to true outcome (for survival data, censoring unlikely to be introducing bias).

- Missing outcome data balanced in numbers across intervention groups, with similar reasons for missing data across groups.

- For dichotomous outcome data, the proportion of missing outcomes compared with observed event risk was not enough to have a clinically relevant impact on the intervention effect estimate.

- For continuous outcome data, plausible effect size (difference in means or standardised difference in means) among missing outcomes was not enough to have a clinically relevant impact on observed effect size.

- Missing data have been imputed using appropriate methods.

\section{High risk of bias}

Any one of the following.

- Reason for missing outcome data likely to be related to true outcome, with either imbalance in numbers or reasons for missing data across intervention groups.

- For dichotomous outcome data, the proportion of missing outcomes compared with observed event risk was enough to induce clinically relevant bias in the intervention effect estimate.

- For continuous outcome data, plausible effect size (difference in means or standardised difference in means) among missing outcomes was enough to induce clinically relevant bias in observed effect size.

A 'test and treat' strategy for elevated wound protease activity for healing in venous leg ulcers (Review)

Copyright @ 2016 The Cochrane Collaboration. Published by John Wiley \& Sons, Ltd. 
- 'As-treated' analysis done with substantial departure of the intervention received from that assigned at randomisation.

- Potentially inappropriate application of simple imputation.

Unclear

Either of the following.

- Insufficient reporting of attrition/exclusions to permit a judgement of low or high risk of bias (e.g. number randomised not stated, no reasons for missing data provided).

- The study did not address this outcome.

\section{Are reports of the study free of suggestion of selective outcome reporting?}

\section{Low risk of bias}

Either of the following.

- The study protocol is available and all of the study's pre-specified (primary and secondary) outcomes that are of interest in the review have been reported in the pre-specified way.

- The study protocol is not available but it is clear that the published reports include all expected outcomes, including those that were pre-specified (convincing text of this nature may be uncommon).

\section{High risk of bias}

Any one of the following.

- Not all of the study's pre-specified primary outcomes have been reported.

- One or more primary outcomes are reported using measurements, analysis methods or subsets of the data (e.g. subscales) that were not pre-specified.

- One or more reported primary outcomes of the study were not pre-specified (unless clear justification for their reporting is provided, such as an unexpected adverse effect).

- One or more outcomes of interest in the review are reported incompletely so that they cannot be entered in a meta-analysis.

- The study report fails to include results for a key outcome that would be expected to have been reported for such a study.

\section{Unclear}

Insufficient information provided to permit judgement of low or high risk of bias. It is likely that the majority of studies will fall into this category.

\section{Other sources of potential bias}

\section{Low risk of bias}

The study appears to be free of other sources of bias.

\section{High risk of bias}

There is at least one important additional risk of bias. For example, the study:

- had a potential source of bias related to the specific study design used; or

- has been claimed to have been fraudulent; or

- had some other problem.

\section{Unclear}

There may be a risk of bias, but there is either:

- insufficient information to assess whether an important risk of bias exists; or

- insufficient rationale or evidence that an identified problem will introduce bias. 


\section{Appendix 3. Risk of bias in cluster randomised trials}

In cluster randomised trials, particular biases to consider include: (i) recruitment bias; (ii) baseline imbalance; (iii) loss of clusters; (iv) incorrect analysis; and (v) comparability with individually randomised trials.

(i) Recruitment bias can occur when individuals are recruited to the trial after the clusters have been randomised, as the knowledge of whether each cluster is an 'intervention' or 'control' cluster could affect the types of participants recruited.

(ii) Cluster randomised trials often randomise all clusters at once, so lack of concealment of an allocation sequence should not usually be an issue. However, because small numbers of clusters are randomised, there is a possibility of chance baseline imbalance between the randomised groups, in terms of either the clusters or the individuals. Although not a form of bias as such, the risk of baseline differences can be reduced by using stratified or pair-matched randomisation of clusters. Reporting of the baseline comparability of clusters, or statistical adjustment for baseline characteristics, can help to reduce concern about the effects of baseline imbalance.

(iii) Occasionally complete clusters are lost from a trial, and have to be omitted from the analysis. Just as for missing outcome data in individually randomised trials, this may lead to bias. In addition, missing outcomes for individuals within clusters may also lead to a risk of bias in cluster randomised trials.

(iv) Many cluster randomised trials are analysed by incorrect statistical methods, not taking the clustering into account. Such analyses create a 'unit of analysis error' and produce over-precise results (the standard error of the estimated intervention effect is too small) and $\mathrm{P}$ values that are too small. They do not lead to biased estimates of effect. However, if they remain uncorrected, they will receive too much weight in a meta-analysis.

(v) In a meta-analysis including both cluster and individually randomised trials, or including cluster randomised trials with different types of clusters, possible differences between the intervention effects being estimated need to be considered. For example, in a vaccine trial of infectious diseases, a vaccine applied to all individuals in a community would be expected to be more effective than if the vaccine was applied to only half of the people. Another example is provided by a discussion of a Cochrane review of hip protectors (Hahn 2005). The cluster trials showed large positive effect whereas individually randomised trials did not show any clear benefit. One possibility is that there was a 'herd effect' in the cluster randomised trials (which were often performed in nursing homes, where compliance with using the protectors may have been enhanced). In general, such 'contamination' would lead to underestimates of effect. Thus, if an intervention effect is still demonstrated despite contamination in those trials that were not cluster randomised, a confident conclusion about the presence of an effect can be drawn. However, the size of the effect is likely to be underestimated. Contamination and 'herd effects' may be different for different types of cluster.

\section{CONTRIBUTIONSOFAUTHORS}

Gill Norman: designed and co-ordinated the review, analysed and interpreted data, contacted manufacturers, completed first draft of the review, approved the final version of the review prior to submission and is a guarantor of the review.

Maggie Westby: designed the review, analysed and interpreted data, performed part of the writing and editing of the review and approved the final version of the review prior to submission.

Nikki Stubbs: advised on the review, made an intellectual contribution to the review and approved the final version of the review prior to submission

Jo Dumville: conceived and designed the review; secured funding for the review; analysed and interpreted data; performed part of the writing and editing of the review; approved the final version of the review prior to submission and is a guarantor of the review.

Nicky Cullum: analysed and interpreted data, advised on the review, performed part of the writing and editing of the review, approved the final version of the review prior to submission.

\section{Contributions of editorial base:}

Andrea Nelson, Editor: advised on methodology, interpretation and content. Approved the final review prior to submission. Sally Bell-Syer and Gill Rizzello, Managing Editors: coordinated the editorial process. Advised on content. Edited the review. Rocio Rodriguez-Lopez, Trials Search Co-ordinator: designed the search strategy and edited the search methods section.

A 'test and treat' strategy for elevated wound protease activity for healing in venous leg ulcers (Review) 


\section{DECLARATIONSOF INTEREST}

Nicky Cullum: none known.

Jo Dumville: none known.

Gill Norman: My employment at the University of Manchester is supported by a grant from National Institute for Health Research, UK (NIHR Cochrane Programme Grant 13/89/08-High Priority Cochrane Reviews in Wound Prevention and Treatment).

Nikki Stubbs Funding from pharmaceutical companies supports training and education events in the service and payments have been received by the author for non product related educational sessions. These have been unrelated to the subject matter of the systematic review and have never been in support or in pursuit of the promotion of products.

Maggie Westby My current employment at the University of Manchester is funded by NIHR and focuses on high priority Cochrane reviews in the prevention and treatment of wounds. In my previous employment at the Royal College of Physicians, I worked on methods for test and treat reviews and conducted two reviews for NICE and KCE guidelines (no financial conflicts of interest).

\section{SOURCES OF SUPPORT}

\section{Internal sources}

- School of Nursing, Midwifery and Social Work, University of Manchester, UK.

Editorial base and additional support.

- Department of Health Sciences, University of York, UK.

Editorial base.

\section{External sources}

- National Institute for Health Research, UK.

This project was supported by the National Institute for Health Research, via Cochrane Infrastructure and Cochrane Programme Grant funding (NIHR Cochrane Programme Grant 13/89/08 - High Priority Cochrane Reviews in Wound Prevention and Treatment) to Cochrane Wounds. The views and opinions expressed herein are those of the authors and do not necessarily reflect those of the Systematic Reviews Programme, NIHR, National Health Service or the Department of Health.

\section{DIFFERENCES BETWEEN PROTOCOLANDREVIEW}

This is currently an empty review: the original methods have been left as planned in the protocol (Norman 2015) to facilitate population of the review with data in the future. 